\title{
Eye-Movement Intervention Enhances Extinction via Amygdala Deactivation
}

\author{
-Lycia D. de Voogd, ${ }^{1}$ Jonathan W. Kanen, ${ }^{1,3}$ @David A. Neville, ${ }^{1}$ @Karin Roelofs, ${ }^{1,2}$ Guillén Fernández, ${ }^{1}$ \\ and Erno J. Hermans ${ }^{1}$ \\ ${ }^{1}$ Donders Institute for Brain, Cognition, and Behavior, Radboud University and Radboud University Medical Center, 6500 HB, Nijmegen, The Netherlands, \\ ${ }^{2}$ Behavioral Science Institute, Radboud University, $6500 \mathrm{HE}$, Nijmegen, The Netherlands, and ${ }^{3}$ Behavioral and Clinical Neuroscience Institute, Department \\ of Psychology, University of Cambridge, Cambridge CB2 3EB, United Kingdom
}

Improving extinction learning is essential to optimize psychotherapy for persistent fear-related disorders. In two independent studies (both $n=24$ ), we found that goal-directed eye movements activate a dorsal frontoparietal network and transiently deactivate the amygdala $\left(\eta_{p}^{2}=0.17\right)$. Connectivity analyses revealed that this downregulation potentially engages a ventromedial prefrontal pathway known to be involved in cognitive regulation of emotion. Critically, when eye movements followed memory reactivation during extinction learning, it reduced spontaneous fear recovery $24 \mathrm{~h}$ later $\left(\eta_{p}^{2}=0.21\right)$. Stronger amygdala deactivation furthermore predicted a stronger reduction in subsequent fear recovery after reinstatement $(r=0.39)$. In conclusion, we show that extinction learning can be improved with a noninvasive eye-movement intervention that triggers a transient suppression of the amygdala. Our finding that another task which taxes working memory leads to a similar amygdala suppression furthermore indicates that this effect is likely not specific to eye movements, which is in line with a large body of behavioral studies. This study contributes to the understanding of a widely used treatment for traumatic symptoms by providing a parsimonious account for how working-memory tasks and goal-directed eye movements can enhance extinction-based psychotherapy, namely through neural circuits (e.g., amygdala deactivation) similar to those that support cognitive control of emotion.

Key words: amygdala; cognitive control; extinction learning; eye movement desensitization and reprocessing (EMDR); functional MRI; Pavlovian fear conditioning

\section{Significance Statement}

Fear-related disorders represent a significant burden on individual sufferers and society. There is a high need to optimize treatment, in particular via noninvasive means. One potentially effective intervention is execution of eye movements following trauma recall. However, a neurobiological understanding of how eye movements reduce traumatic symptoms is lacking. We demonstrate that goal-directed eye-movements, like working-memory tasks, deactivate the amygdala, the core neural substrate of fear learning. Effective connectivity analyses revealed amygdala deactivation potentially engaged dorsolateral and ventromedial prefrontal pathways. When applied during safety learning, this deactivation predicts a reduction in later fear recovery. These findings provide a parsimonious and mechanistic account of how behavioral manipulations taxing working memory and suppressing amygdala activity can alter retention of emotional memories.

\section{Introduction}

Extinction learning is core to most effective therapies for disorders of fear and anxiety (Bisson et al., 2013). Exposure therapy,

This work was supported by Grants from the EMDR Research Foundation and the European Research Council (ERC-2015-CoG 682591). Funding sources had no role in study design, data analysis, or writing of the paper. We for instance, results in the formation of an extinction memory that suppresses fear expression. Relapse of pathological fear is nevertheless common (Maren, 2011; Dunsmoor et al., 2015b). Improving extinction learning is therefore an important goal of

thank Sasha Bouman, Frederiek Wijers, and Juul Willering for expert advice on EMDR, and Laura van Weerdenburg for help with data collection.

The authors declare no competing financial interests.

Correspondence should be addressed to Lycia D. de Voogd, Donders Institute for Brain, Cognition and Behavior (Radboudumc), P.0. Box 9101, 6500 HB Nijmegen, The Netherlands. E-mail: devoogd.Id@gmail.com. DOl:10.1523/JNEUROSCI.0703-18.2018

Copyright $\odot 2018$ the authors $\quad 0270-6474 / 18 / 388694-13 \$ 15.00 / 0$ 
translational research into fear-related disorders (Dunsmoor et al., 2015b). Pharmacological treatments have proven effective in preventing fear recovery in animal models (Nader et al., 2000), but these methods are often not applicable in humans (Nader et al., 2000) or have yielded inconsistent results in experimental models with humans (Kindt et al., 2009; Bos et al., 2012). New noninvasive techniques have been developed that target reconsolidation of the original memory rather than enhance standard extinction learning (Schiller et al., 2010). Although these results are promising, their clinical utility is so far unclear.

Clinically effective treatments are not always derived from such experimental models. One example is eye movement desensitization and reprocessing (EMDR; Bisson et al., 2013), an evidence-based therapy and part of mental health care guidelines in many countries (Bisson et al., 2013; Lee and Cuijpers, 2013). Despite its wide use, a mechanistic, neurobiological understanding of EMDR is lacking. During treatment, patients divide their attention between recalling traumatic memories and making lateral eye movements directed by the therapist's hand. Eye movements are central to the procedure, but it is unclear whether they play any role in the therapeutic outcome above normal extinction (Lee and Cuijpers, 2013). Insight into the potential role of eye movements and the neurobiological mechanisms underlying this manipulation is not only crucial to further optimize this therapy but would also importantly advance our fundamental understanding of extinction learning.

One lead into a neural mechanistic account is that goaldirected eye movements are associated with activations in the dorsal frontoparietal network, including frontal eye fields (FEFs; Corbetta and Shulman, 2002), similar to working-memory tasks that require goal-directed attention. Critically, working-memory tasks are accompanied by robust deactivations in a posteriormedial network (Qin et al., 2009), including the amygdala. Interestingly, a similar activation of the dorsal frontoparietal network and deactivation of the amygdala has been found during cognitive regulation of emotion as well (Ochsner and Gross, 2005). This is important because targeting the amygdala following memory reactivation, by blocking protein synthesis, prevents fear recovery in rodents (Nader et al., 2000). Similarly, systemic administration of propranolol, a $\beta$-adrenoceptor antagonist, presumably exerts its effects on fear recovery via inhibition of protein synthesis in the amygdala (Dębiec and Ledoux, 2004). Amygdala reactivity measured with blood oxygenation leveldependent (BOLD)-fMRI in humans is furthermore decreased after propranolol administration (Hurlemann et al., 2010). Indeed, it has been shown that working memory-like tasks, such as a game of Tetris (Holmes et al., 2009; James et al., 2015) can affect the emotionality of memories. We therefore hypothesized (1) that goal-directed eye movements could be used as a noninvasive tool to transiently suppress amygdala activity, comparable to working-memory tasks, and (2) that a well timed application of this deactivation following memory reactivation could reduce fear recovery.

To test our hypotheses, in experiment $1(n=24)$, participants performed a two-back working-memory task and goal-directed eye movements in a block design while undergoing functional MRI. We tested whether both tasks would suppress amygdala activity as well as alter the coupling between the amygdala and dorsal lateral prefrontal cortex. In the second experiment $(n=$ 24), we integrated eye movements into an established Pavlovian fear conditioning/extinction/recall paradigm and tested whether goal-directed eye movements prevent fear recovery via this amygdala deactivation.

\section{Materials and Methods}

\section{Experiment 1}

Participants. Twenty-four right-handed healthy volunteers (12 females, 12 males; $23-37$ years; $\mathrm{M}=26.95, \mathrm{SD}=3.6$ ) completed the study. Exclusion criteria were any contraindications for MRI. All gave written informed consent and were paid for their participation. This study was approved by the local ethical review board (CMO region Arnhem-Nijmegen).

Experimental design. The tasks consisted of six blocks of a two-back working-memory task (Qin et al., 2009), six blocks of smooth-pursuit lateral eye movement task, and an additional eight blocks of low-level fixation baseline. The duration of each block was $27 \mathrm{~s}$. Within each twoback block, participants saw a random sequence consisting of 15 single digits. Each digit was presented for $400 \mathrm{~ms}$, followed by an interstimulus interval (ISI) of $1400 \mathrm{~ms}$. Participants were asked to detect whether the current item had appeared two positions back in the sequence and were instructed to make a button press when detecting a target. For the eyemovement blocks, participants were instructed to follow a laterally moving dot with their eyes. The speed of the eye movements was $\sim 1 \mathrm{~Hz}$, based on previous laboratory models of EMDR (van den Hout et al., 2013). See Fig. 1.

MRI data acquisition. MRI scans were acquired using a Siemens MAGNETOM Skyra 3T MR scanner. T2*-weighted BOLD images were recorded using a customized EPI sequence with ascending slice acquisition [ 37 axial slices; $\mathrm{TR}=1.89 \mathrm{~s}, \mathrm{TE}=25 \mathrm{~ms}$, generalized autocalibrating partially parallel acquisitions (GRAPPA), Griswold et al., 2002; acceleration factor $=2$; flip angle $=90^{\circ}$; slice matrix size $=64 \times 64$; slice thickness $=3.3 \mathrm{~mm}$; slice gap $=0.3 \mathrm{~mm} ; \mathrm{FOV}=212 \times 212 \mathrm{~mm}$; bandwidth: $1776 \mathrm{~Hz} / \mathrm{px}$; echo spacing: $0.65 \mathrm{~ms}$ ]. A structural image ( $1 \mathrm{~mm}$ isotropic) was acquired using a T1-weighted 3D magnetization-prepared rapid gradient-echo sequence $(\mathrm{MP}-\mathrm{RAGE} ; \mathrm{TR}=2.73 \mathrm{~s}$, TE $=2.95 \mathrm{~ms}$, flip angle $=7, \mathrm{FOV}=256 \times 256 \times 176 \mathrm{~mm})$.

MRI data preprocessing and statistical analyses. MRI data were preprocessed in standard stereotactic (MNI152) space for the purpose of whole-brain group analyses. Mutual information maximization-based rigid-body registration was used to register structural and functional images. Functional images were motion corrected using rigid-body transformations. Structural images were segmented into gray matter, white matter, and CSF images using a unified probabilistic template registration and tissue classification method (Ashburner and Friston, 2005). Tissue images were then registered with site-specific tissue templates (created from 384 T1-weighted scans) using DARTEL (Ashburner, 2007), and registered (using an affine transformation) with the MNI152 template included in SPM8 (RRID: SCR_007037). Identical transformations were applied to all functional images, which were resliced into $2 \mathrm{~mm}$ isotropic voxels and smoothed with a 6 mm FWHM Gaussian kernel.

Responses to the two-back task and lateral eye movements were modeled using boxcar regressors (duration of $27 \mathrm{~s}$ ). These two regressors were temporally convolved with the canonical hemodynamic response function (HRF) included in SPM8 (RRID:SCR_007037). Additionally, six movement parameter regressors (3 translations, 3 rotations) derived from rigid-body motion correction, high-pass filtering $(1 / 128 \mathrm{~Hz}$ cutoff), and AR(1) serial correlation corrections were included in the model. Single-subject contrast maps of the two-back and eye-movement blocks against fixation were entered into second-level one-sample $t$ tests.

Finally, we conducted a psychophysiological interaction (PPI) analysis with the amygdala (left and right separately) as seeds for both the eyemovement condition and the two-back condition. We performed the PPI analysis in Experiment 1, because here we used a blocked design, which is optimal for investigating task-driven connectivity changes on top of task activation (Friston et al., 1997). These (four) first level models were identical to the model described above, but each included two additional regressors namely (1) the time series for the first eigenvariate of the amygdala seed (either left or right), and (2) the product of this time series (after HRF deconvolution) with task regressor (either the two-back blocks or the eye movement blocks versus fixation) that was temporally convolved with the canonical HRF included in SPM8 (RRID: SCR_007037). Single-subject contrast maps of the two-back and eyemovement blocks against fixation were entered into second-level full 
A

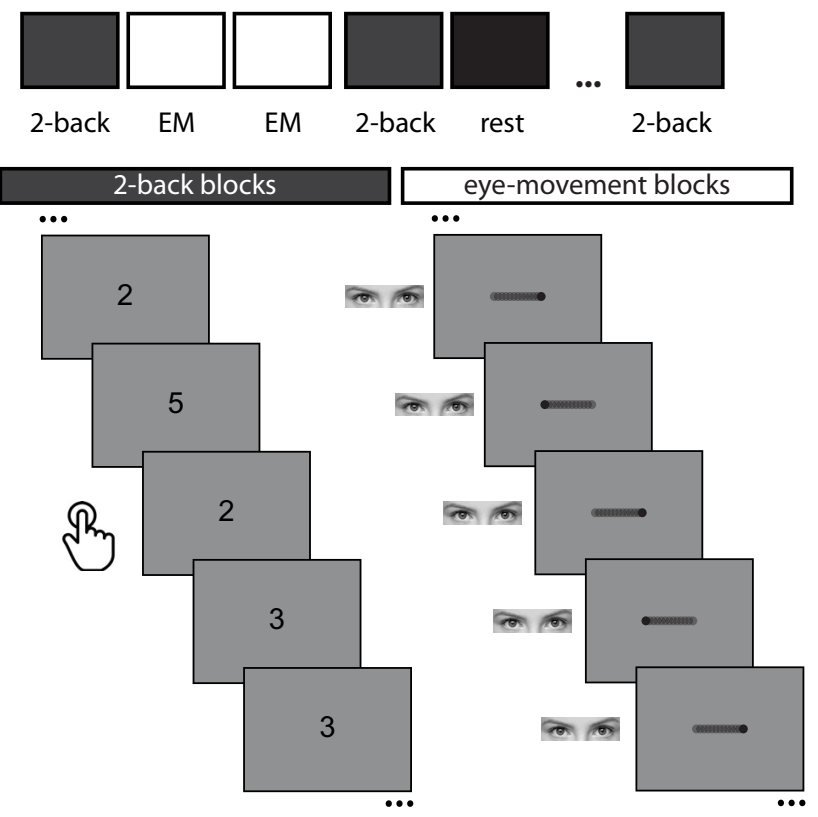

C
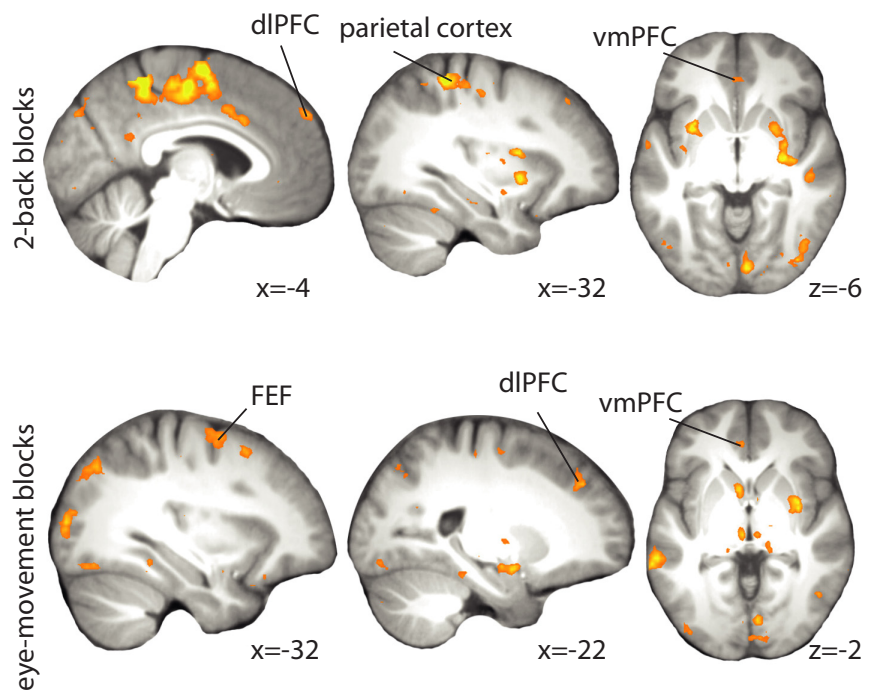

amygdala seed

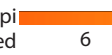

6.5

7.5

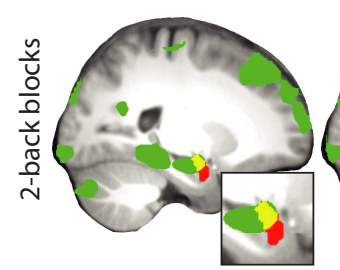

$x=-22$

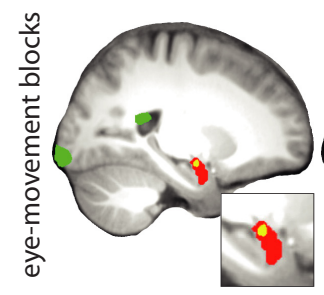

$x=-22$
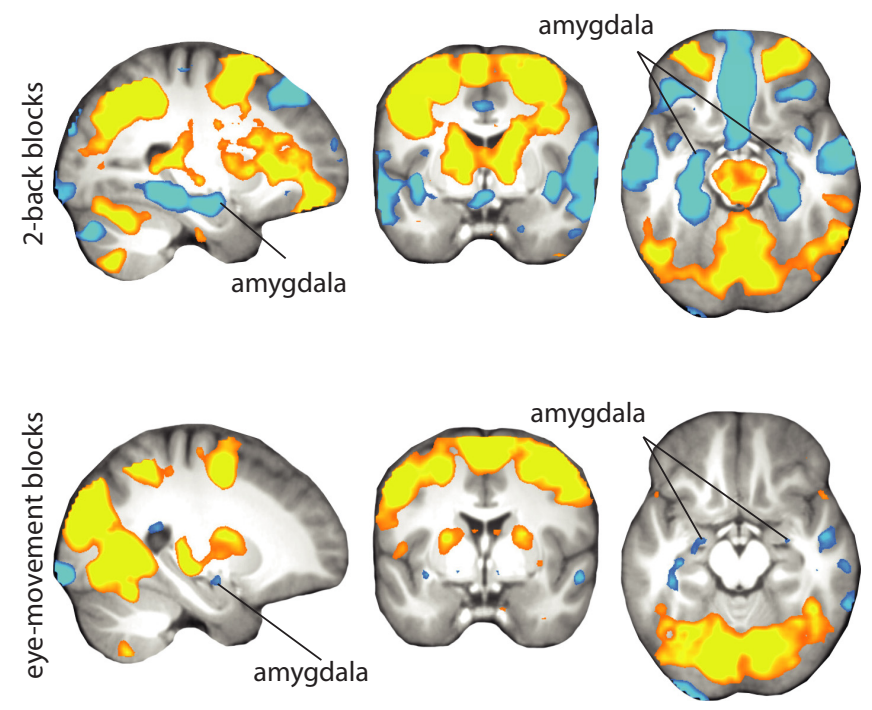

activation

deactivation 3.2

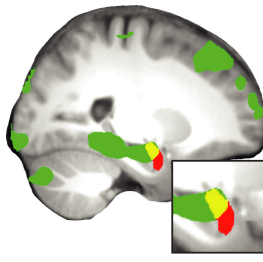

$x=-23$

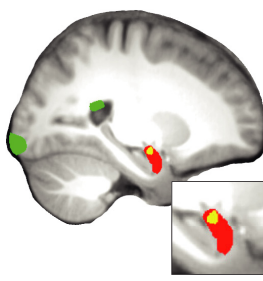

$x=-23$

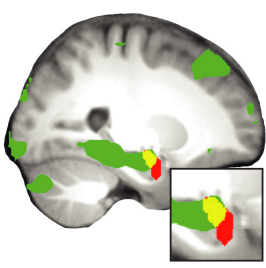

$x=-24$

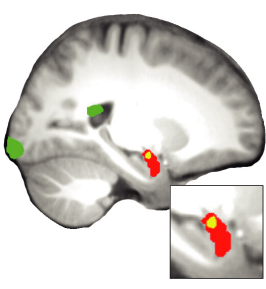

$x=-24$

Figure 1. A, Experimental design. $B$, Activations and deactivations of the two-back task and eye movements compared with fixation. The threshold for significance for the amygdala (whole-brain threshold $p<0.005$ uncorrected and peak voxel FWE-SVC $p<0.05)$ is applied to the whole brain to show the specificity of the effect. Whole-brain corrected inferential statistics are reported in Table 1. C, PPI cluster with the left and right amygdala as a seed for the two-back task and eye movements compared with fixation. Images are thresholded at $p<0.05$, whole-brain FWE-corrected. Whole-brain corrected inferential statistics are reported in Table 2. D, Deactivation during the two-back blocks and eye-movement blocks (in green) overlaid onto the average T1 scan from all participants. In red is the anatomical location of the amygdala. It can be seen that the deactivation (overlap is in yellow) is located toward the dorsal part in both tasks. EM, Eye movements.

factorial repeated-measures ANOVAs with hemisphere as a withinsubject variable.

Based on our a priori hypotheses, results for the amygdala and ventral medial prefrontal cortex (vmPFC) were corrected for reduced search volumes using small volume corrections (SVC) and were familywise error (FWE) corrected using voxel-level statistics. SVC of the amygdala was based on a group mask that was created by averaging individual amygdala segmentations $(n=24)$ of T1-weighted images using FSL FIRST (RRID: SCR_002823; https://fsl.fmrib.ox.ac.uk/fsl/fslwiki/FIRST), which were warped into MNI space using DARTEL. The vmPFC was defined as 10 $\mathrm{mm}$ sphere around the $0,40,-3$ coordinate based on a previous study (Schiller and Delgado, 2010).
Eye tracking. For 15 participants, eye tracking was recorded using an MR-compatible eye-tracking system (MEye Track-LR camera unit, SMI, SensoMotoric Instruments). Data were preprocessed using in-house software (Hermans et al., 2013) implemented in MATLAB 7.14 (MathWorks; RRID:SCR_001622). Blinks were removed from the signal using linear interpolation. Eye-tracking data were normalized based on a calibration at the start of the experiment. Visual inspection revealed participants complied with the instructions of the task.

\section{Experiment 2}

Participants. Twenty-four right-handed healthy volunteers (12 females, 12 males; 20-34 years; $\mathrm{M}=24.8, \mathrm{SD}=3.6$ ) completed the study. An 
additional five participants did not complete the entire experiment due noncompliance with instructions (e.g., falling asleep). Exclusion criteria were as follows: current or lifetime history of psychiatric, neurological, or endocrine illness, current treatment with any medication that affects CNS or endocrine systems, average use of $>3$ alcoholic beverages daily, average use of recreational drugs weekly or more, habitual smoking, predominant left-handedness, uncorrected vision, intense daily physical exercise, and any contraindications for MRI. Participants gave written informed consent and were paid for their participation. This study was approved by the local ethical review board (CMO region Arnhem-Nijmegen).

Experimental design. Participants were tested in a differential delay fear conditioning paradigm (Schiller et al., 2010, 2013) on 3 consecutive days with $24 \mathrm{~h}$ in between. The first day comprised an acquisition session, the second day an extinction session, and the third day a recall session. The stimulus set across the $3 \mathrm{~d}$ consisted of four squares as conditioned stimuli (CS) with a different color. The luminance of the stimuli, background, and ISI screen was equalized. On Day 1 , two cues (CS $+\mathrm{s}$, $4 \mathrm{~s}$ duration) were partially reinforced (37.5\% reinforcement rate) with a mild electrical shock to the fingers [i.e., the unconditioned stimulus (UCS)]. The two other cues (CS-s, 4 s duration) were never reinforced. In total, there were 64 trials (16 trials per CS), including the CS-UCS trials. The CS $+\mathrm{s}$ reinforced, CS $+\mathrm{s}$ unreinforced, and CS-s were presented in a pseudorandom order. The ISI was jittered between 4 and $8 \mathrm{~s}$ with an average of $6 \mathrm{~s}$.

On Day 2, extinction included 48 CS trials ( 12 trials per CS, $4 \mathrm{~s}$ duration) and 24 eye-movement blocks ( $10 \mathrm{~s}$ duration). One $\mathrm{CS}+\left(\mathrm{CS}+{ }_{\text {eye }}\right)$ and one $\mathrm{CS}-\left(\mathrm{CS}-{ }_{\text {eye }}\right)$ were always followed by an eye-movement block, whereas the other $\mathrm{CS}+\left(\mathrm{CS}+{ }_{\text {no-eye }}\right)$ and the other $\mathrm{CS}-\left(\mathrm{CS}-_{\text {no-eye }}\right)$ were always followed by a fixation block. The ISI between CS and eye movement block was jittered between 0.5 and $1.5 \mathrm{~s}$, which was done to minimize eye-movement anticipation during the CS presentation. With the duration of $10 \mathrm{~s}$, we stayed on the lower end of what is used in EMDR treatment, in which the duration of eye movements varies between 8 and $96 \mathrm{~s}$ (Lee and Cuijpers, 2013). This $10 \mathrm{~s}$ duration limits the length of the experiment while still including the peak of the BOLD response within the eye-movement blocks (Heeger and Ress, 2002). As in Experiment 1, the speed of the moving dot was $\sim 1 \mathrm{~Hz}$, based on previous laboratory models of EMDR (van den Hout et al., 2013). The visual angle was $\sim 11^{\circ}$. The ISI after the eye-movement block varied between 4 and $8 \mathrm{~s}$ with an average of 6 s. On Day 3, the experiment started with a re-extinction session (re-extinction 1), which included 24 CS trials ( 6 trials per CS, $4 \mathrm{~s}$ duration) with an ISI jittered between 4 and $8 \mathrm{~s}$ (average of $6 \mathrm{~s}$ ). After this session there was a reinstatement procedure (Haaker et al., 2014) consisting of three unsignaled UCS presentations (ISI: $10 \mathrm{~s}$ ). Following this, participants underwent a second re-extinction session (re-extinction2), which included $24 \mathrm{CS}$ trials ( 6 trials per CS, $4 \mathrm{~s}$ duration). ISI was jittered between 4 and $8 \mathrm{~s}$ with an average of $6 \mathrm{~s}$. See Fig. 2 for an overview.

Questionnaires and debriefing. Participants completed the Beck Depression Inventory (BDI; Beck et al., 1996) and the trait version of StateTrait Anxiety Inventory (STAI-t; Van der Ploeg, 1980). A BDI score $>13$ was used to exclude participants from the analyses, but none of the participants had a score higher than the cutoff. Average BDI score was 3.5 (range: $0-10$ ) and STAI-t was 33.5 (range: 25-48). Participants were debriefed after the completion of the experiment and asked about their contingency knowledge on the occurrence of electrical shocks, as well as the relationship between the CSs and eye-movement blocks. Participants were furthermore asked about their knowledge of EMDR and whether they at some time during the experiment thought of the experiment in the context of EMDR treatment. Five participants reported doing so. We therefore redid the analyses of the two re-extinction phases on Day 3 excluding these five participants. The results and conclusions remained the same and therefore the results are reported including all participants.

Peripheral stimulation. Electrical shocks were delivered via two $\mathrm{Ag} /$ $\mathrm{AgCl}$ electrodes attached to the distal phalanges of the second and third fingers of the right or left hand (counterbalanced between subjects) using a MAXTENS 2000 (Bio-Protech) device. Shock duration was $200 \mathrm{~ms}$, and intensity varied in 10 intensity steps between $0-40 \mathrm{~V} / 0-80 \mathrm{~mA}$. During a standardized shock intensity adjustment procedure, each participant received and subjectively rated five shocks, allowing shock intensity to converge to a level experienced as uncomfortable, but not painful. The resulting average intensity step was 4.8 (SD: 1.8) on a scale from 1 to 10 . The intensity step was set on Day 1 and remained the same on Day 3 for the reinstatement procedure.

Peripheral measurements. Electrodermal activity was assessed using two $\mathrm{Ag} / \mathrm{AgCl}$ electrodes attached to the distal phalanges of the first and second fingers of the left or right hand (counterbalanced between subjects) using a BrainAmp MR system and recorded using BrainVision Recorder software (Brain Products GmbH). Data were preprocessed using in-house software; radio frequency artifacts were removed and a low-pass filter was applied. Skin conductance responses (SCRs) were automatically scored with additional manual supervision using Autonomate (Green et al., 2014) implemented in MATLAB 7.14 (MathWorks; RRID:SCR_001622). We opted to use the magnitude method, because it has been considered the standard method of scoring SCRs for several decades (Edelberg, 1972). SCR amplitudes (measured in microsiemens) were determined for each trial within an onset latency window between 0.5 and $4.5 \mathrm{~s}$ after stimulus onset, with a minimum rise time of $0.5 \mathrm{~s}$ and a maximum rise time of $5 \mathrm{~s}$ after response onset. Reinforced trials were omitted and all other response amplitudes were square-root transformed before statistical analysis. One subject was omitted from the SCR analyses on Day 1 because of failed recordings presumably due to motion of the hand. Four repeated-measures ANOVAs were conducted, one for each experimental phase (acquisition, extinction, re-extinction1, and reextinction2). Each ANOVA included CS (CS+, CS-) and extinction manipulation (eye, no-eye) as within-subject factors. During the extinction and re-extinction phases, an additional within-subject factor was included, namely Time (early, late). Subsequently, differential SCR were calculated (CS+ minus CS - ) to test for differences between the two conditions (eye movement and no-eye movement). To test for spontaneous recovery of fear, the differential response on the last trial of extinction was subtracted from the first differential response during re-extinction1 (Schiller et al., 2010, 2013). The reinstatement recovery index was calculated in a similar way by subtracting the last differential response during re-extinction 1 from the first differential response during re-extinction2 (Schiller et al., 2010, 2013). For the spontaneous recovery index and reinstatement recovery index analyses, we covaried the order of the CS $+\left(\mathrm{CS}+_{\text {eye }}\right.$ or $\left.\mathrm{CS}+_{\text {no-eye }}\right)$ presentation. Last, the amount of amygdala suppression that occurred on Day 2 during the eye-movement blocks was added as a covariate to the recovery index analyses on Day 3 to test whether amygdala deactivation predicted fear recovery.

Eye tracking was recorded using an MR-compatible eye-tracking system (MEye Track-LR camera unit, SMI, SensoMotoric Instruments). Data were preprocessed using in-house software (Hermans et al., 2013) implemented in MATLAB 7.14 (MathWorks; RRID:SCR_001622). Blinks were removed from the signal using linear interpolation. Eyetracking data during the eye-movement blocks were normalized based on a calibration at the start of the experiment. Visual inspection revealed participants complied with the instructions of the task (see Fig. 3C).

Physiological noise correction. Finger pulse was recorded using a pulse oximeter affixed to the third finger of the left or right hand (counterbalanced between subjects). Respiration was measured using a respiration belt placed around the participant's abdomen. Pulse and respiration measures were used for retrospective image-based correction (RETROICOR) of physiological noise artifacts in BOLD-fMRI data (Glover et al., 2000). Raw pulse and respiratory data were processed offline using in-house software for interactive visual artifact correction and peak detection, and were used to specify fifth-order Fourier models of the cardiac and respiratory phase-related modulation of the BOLD signal (van Buuren et al., 2009), yielding 10 nuisance regressors for cardiac noise and 10 for respiratory noise. Additional regressors were calculated for heart rate frequency, heart rate variability, (raw) abdominal circumference, respiratory frequency, respiratory amplitude, and respiration volume per unit time (Birn et al., 2006), yielding a total of 26 RETROICOR regressors.

MRI data acquisition and multiecho weighting. MRI scans were acquired using a Siemens MAGNETOM Avanto 1.5T MR scanner. T2*weighted BOLD images were recorded using a customized multiecho EPI sequence with ascending slice acquisition ( 35 axial slices; TR $=2.2 \mathrm{~s}$; 
A
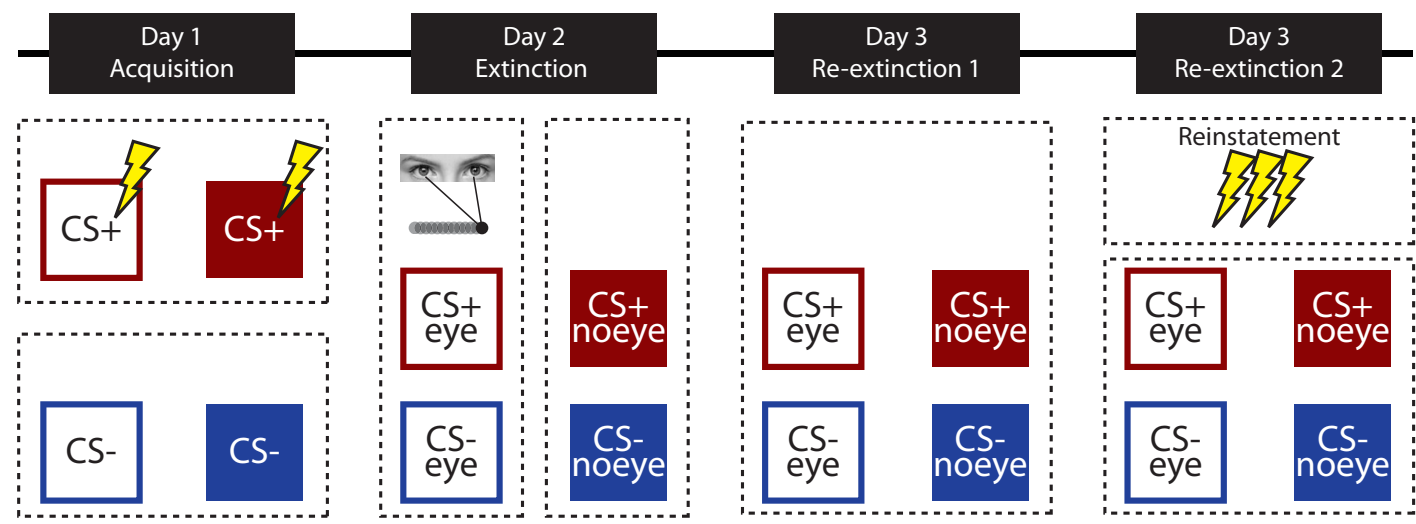

B Eye movements during extinction

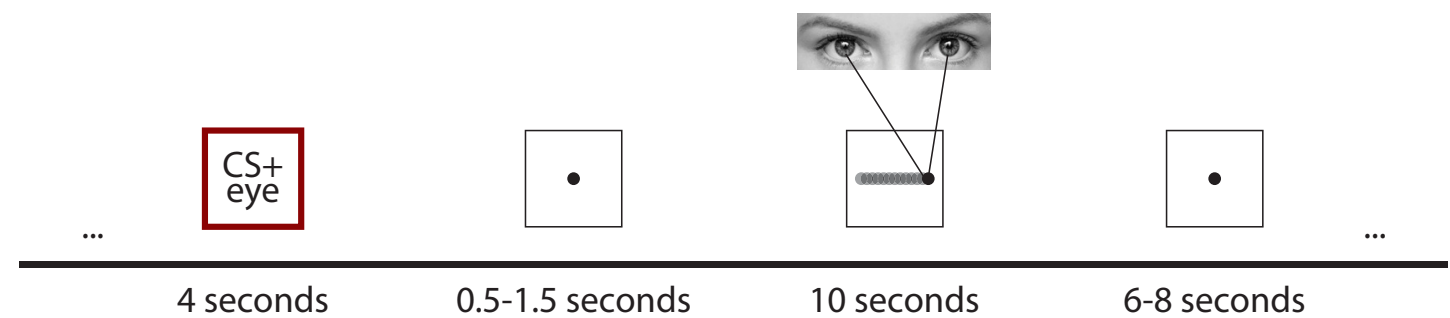

Figure 2. Overview of the experimental design. $\boldsymbol{A}$, The experiment took place on 3 consecutive days and included an acquisition phase (Day 1 ), an extinction phase (Day 2), and a re-extinction (re-extinction1) phase and re-extinction after reinstatement (re-extinction2) phase (Day 3). $\boldsymbol{B}$, Timeline of a single trial during extinction when participants made eye movements.

$\mathrm{TE}=9.4,21,33,44$, and $56 \mathrm{~ms}$, GRAPPA, Griswold et al., 2002; acceleration factor $=3$; flip angle $=90^{\circ}$; slice matrix size $=64 \times 64$; slice thickness: $3.0 \mathrm{~mm}$; slice gap: $0.51 \mathrm{~mm}$; FOV: $212 \times 212 \mathrm{~mm}$; bandwidth: $2604 \mathrm{~Hz} / \mathrm{px}$; echo spacing: $0.49 \mathrm{~ms}$ ). To account for regional variation in susceptibility-induced signal dropout, voxelwise weighted sums of all echoes were calculated based on local contrast-to-noise ratio (Poser et al., 2006). A structural image ( $1 \mathrm{~mm}$ isotropic) was acquired using a T1weighted 3D MP-RAGE $\left(\mathrm{TR}=2.73 \mathrm{~s}, \mathrm{TE}=2.95 \mathrm{~ms}\right.$, flip angle: $7^{\circ}$, FOV: $256 \times 256 \times 176 \mathrm{~mm})$.

MRI data preprocessing in standard stereotactic space and statistical analyses. MRI data were preprocessed in standard stereotactic (MNI152) space for the purpose of whole-brain group analyses. Mutual information maximization-based rigid-body registration was used to register structural and functional images. Functional images were motion corrected using rigid-body transformations. Structural images were segmented into gray matter, white matter, and CSF images using a unified probabilistic template registration and tissue classification method (Ashburner and Friston, 2005). Tissue images were then registered with site-specific tissue templates using DARTEL (Ashburner, 2007), and registered (using an affine transformation) with the MNI152 template included in SPM8 (RRID:SCR_007037). Identical transformations were applied to all functional images, which were resliced into $2 \mathrm{~mm}$ isotropic voxels and smoothed with a $6 \mathrm{~mm}$ FWHM Gaussian kernel.

We created four first-level models for all stages of the experiment (i.e., acquisition, extinction, re-ectinction 1 and re-extinction2). Responses to the CSs were modeled using boxcar regressors (duration of $5 \mathrm{~s}$ ). During the acquisition phase, additional regressors included the reinforced $\mathrm{CS}+\mathrm{s}$ (duration of $5 \mathrm{~s}$ ) and the shock which was modeled as a stick function. During the extinction phase, responses to the eye-movement blocks were modeled using boxcar regressors with a duration of $10 \mathrm{~s}$. Regressors were temporally convolved with the canonical HRF included in SPM8 (RRID:SCR_007037). Additionally, six movement parameter regressors ( 3 translations, 3 rotations) derived from rigid-body motion correction, high-pass filtering (1/128 Hz cutoff), and AR(1) serial correlation corrections were included in the model. Single-subject contrast maps were entered into second-level one-sample $t$ tests.

Although a PPI analysis in experiments with event-related designs is more difficult to interpret (O’Reilly et al., 2012), we did perform a PPI analysis, similar to Experiment 1, with the amygdala as a seed region in Experiment 2 as well. We did not find any statistically significant connectivity changes. As an extra check, we used the FEF as a seed as well, but also here we did not observe reliable connectivity differences. Additionally, we applied a $\beta$ series correlation (Rissman et al., 2004) with the amygdala as a seed region. However, we did not find any statistically significant connectivity changes using this method either. There are two possible explanations for this null finding. First, the shape and assumptions regarding the HRF are more important in event-related designs than in blocked designs (Gitelman et al., 2003). Second, in the period where it is possible to look at task-driven connectivity changes in event-related designs are shorter than in blocked designs. Thus, PPI analyses have less power than task activity analyses and tend to have smaller effect sizes than blocked designs.

Based on our priori hypotheses, results for the amygdala and dorsal anterior cingulate cortex (dACC) were corrected for reduced search volumes using small volume corrections (SVC) and were FWE-corrected using voxel-level statistics. SVC of the amygdala was based on a group mask that was created by averaging individual amygdala segmentations $(n=24)$ of T1-weighted images (using FSL FIRST; RRID:SCR_002823; https://fsl.fmrib.ox.ac.uk/fsl/fslwiki/FIRST), which were warped into MNI space using DARTEL. The dACC was defined based on a functional ROI atlas (Shirer et al., 2012).

MRI data preprocessing of the extinction session in native space and statistical analyses. For the primary fMRI analysis (amygdala response during eye movements), we preprocessed MRI data during extinction in native space (i.e., without stereotactic normalization) using SPM8 (RRID:SCR_007037; http://www.fil.ion.ucl.ac.uk/spm; Wellcome Department of Imaging Neuroscience, London, UK). Because the results from Experiment 1 showed the suppression was not specific to the amygdala, we opted for this more specific analysis to make sure that the amygdala effects are not, for example, due to signal blurring from the hippocampus into the amygdala. Additionally, this analysis allowed us to extract an averaged time course of the amygdala signal.

All functional scans were coregistered with structural scans using mutual information maximization. The amygdala was individually defined in native space using automated anatomical segmentation of T1-weighted images using FSL FIRST (RRID:SCR_002823; https://fsl.fmrib.ox.ac.uk/ fsl/fslwiki/FIRST). The amygdala segmentations underwent visual in- 
A

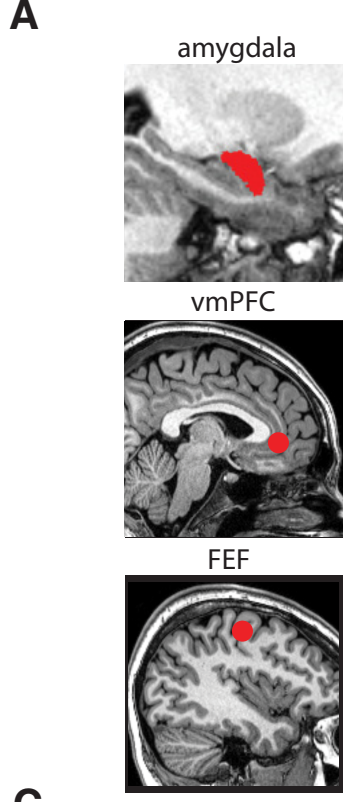

C
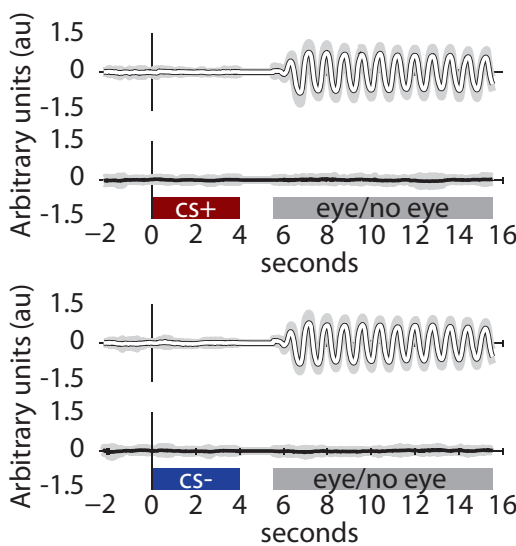

B

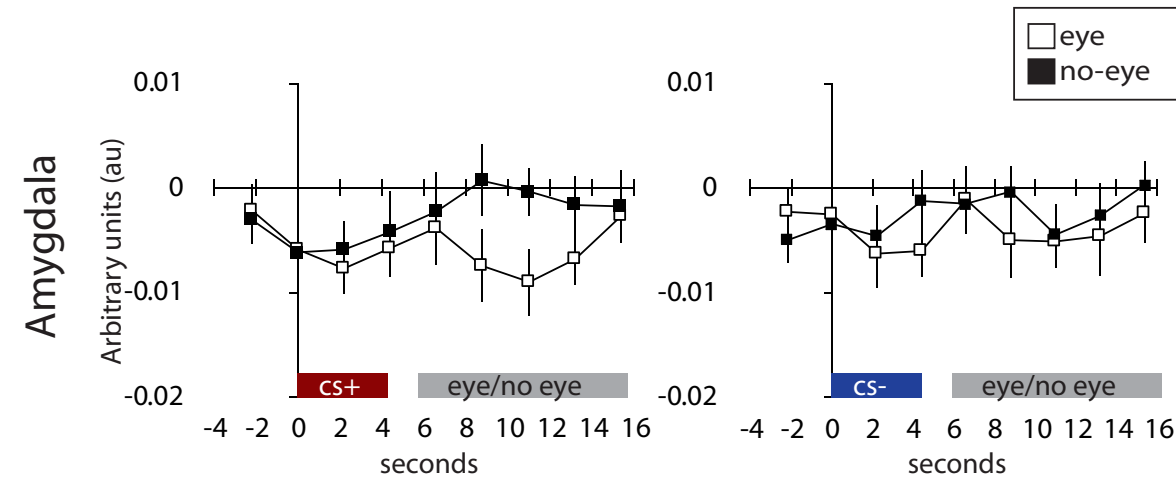

0.01

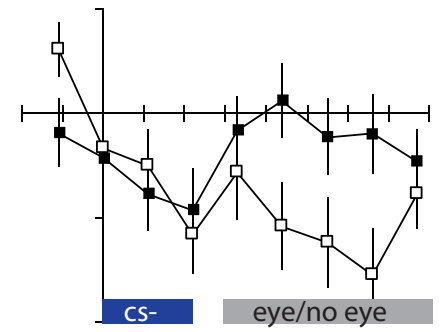

$\begin{array}{llllllllllll}-4 & -2 & 0 & 2 & 4 & 6 & 8 & 10 & 12 & 14 & 16\end{array}$ seconds
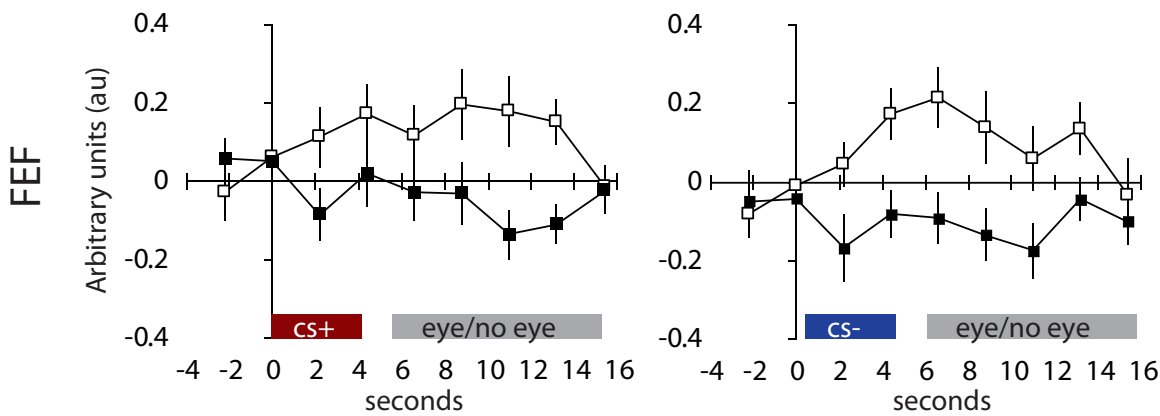

Figure 3. Eye movements suppress amygdala activity. $\boldsymbol{A}$, Single-subject example of the automated amygdala segmentation, vmPFC, was defined by a $10 \mathrm{~mm}$ radius around the $0,40,-3$ coordinate (Schiller and Delgado, 2010) and FEF as a bilateral $5 \mathrm{~mm}$ radius around the MNI peak coordinates reported in a meta-analysis of neuroimaging studies of eye movements (Jamadar et al., 2013). B, Amygdala and vmPFC deactivation and FEF activation during eye-movement and no-eye movement blocks within the extinction phase. Error bars represent \pm SEM. C, Eye-movement recordings during eye-movement and no-eye movement blocks within the extinction phase. The black and white lines reflect the mean across all participants and the gray shaded area the SEM. Eye, Eye movements; No-eye, no-eye movements.

spection. We observed that some amygdala voxels for some participants were not part of the mask, indicating that the FSL FIRST segmentation was relatively conservative (e.g., in anterior parts; Moore et al., 2014). For each participant, we made sure that the amygdala mask did not contain voxels that were part of, or extended into, the hippocampus. We therefore conclude that our amygdala masks are representative of amygdala volume, and that the suppression effect can be assigned to the amygdala. The vmPFC was defined as $10 \mathrm{~mm}$ sphere around the $0,40,-3$ coordinate based on a previous study (Schiller and Delgado, 2010). The FEFs were defined based on a $5 \mathrm{~mm}$ sphere around the MNI peak coordinates reported in a meta-analysis (Jamadar et al., 2013). Subsequently, the FEF masks were transferred back into native space for each individual using the reversed spatial normalization parameters.

For statistical analyses, responses to the eye-movement and no-eye movement blocks were estimated using a finite impulse response model which included nine time bins ( $\mathrm{TR}=2.2 \mathrm{~s}$ ) starting one time-bin before the onset of the CS $(-2.2 \mathrm{~s})$ and ending one time bin after the eyemovement blocks (17.6 s). Therefore, bin numbers 5-8 (6.6-15.4 s) always fell within the eye-movement blocks. For the no-eye movement block, the same time frame was used. This first-level model makes no assumptions regarding the HRF shape and yields independent response estimates for all nine time bins, which makes it possible to investigate the time course of the responses. The first-level models additionally included six movement parameter regressors ( 3 translations, 3 rotations) derived from rigid-body motion correction, 26 RETROICOR physiological noise regressors (see MRI data preprocessing in standard stereotactic space and statistical analyses), high-pass filtering (1/128 Hz cutoff), and AR(1) serial correlations correction. We extracted the average $\beta$ weights within the amygdala and FEF for each time bin and each CS. A repeatedmeasures ANOVA was conducted for each region with CS (CS+, CS-), extinction manipulation (eye, no-eye), and time bin (5-8) as withinsubject factors (see Fig. 3).

Statistical analysis. Sample size of 24 was determined based a pooled effect size from four studies that have used similar paradigms (Schiller et al., 2010, 2013; Agren et al., 2012; Kindt and Soeter, 2013), $\alpha=0.05$, and $1-\beta=0.80$. Partial $\eta$-squared $\left(\eta_{p}^{2}\right)$ or Cohen's $d$ effect size estimates are reported for all relevant tests. Alpha was set at 0.05 throughout and two-tailed $t$ tests were conducted unless stated otherwise. Statistical analyses were performed using SPSS 19 (IBM; RRID:SCR_002865), MATLAB 7.14 (MathWorks; RRID:SCR_001622), and SPM8 (RRID: SCR_007037; http://www.fil.ion.ucl.ac.uk/spm; Wellcome Department 
Table 1. Peak voxel coordinates and statistics of activations and deactivations of the two-back task and eye movements compared to fixation (Experiment 1 )

\begin{tabular}{|c|c|c|c|c|c|c|}
\hline Region & Side & $x, \mathrm{~mm}$ & $y, m m$ & $\mathrm{z}, \mathrm{mm}$ & Peak T & $p$ value \\
\hline \multicolumn{7}{|l|}{ Two-back blocks $>$ fixation ${ }^{a}$} \\
\hline Anterior insula & $\mathrm{R}$ & 34 & 26 & 0 & 14.70 & $<0.001$ \\
\hline \multirow[t]{2}{*}{ Dorsolateral prefrontal cortex } & L & -40 & 2 & 30 & 8.57 & $<0.001$ \\
\hline & $\mathrm{R}$ & 44 & 38 & 24 & 7.16 & $<0.001$ \\
\hline \multirow[t]{2}{*}{ Posterior parietal cortex } & L & -34 & -56 & 50 & 11.63 & $<0.001$ \\
\hline & $\mathrm{R}$ & 48 & -36 & 46 & 11.88 & $<0.001$ \\
\hline \multicolumn{7}{|l|}{ Two-back blocks $<$ fixation } \\
\hline Superior frontal gyrus & L & -18 & 42 & 46 & 13.38 & $<0.001$ \\
\hline Precuneus & L & -4 & -52 & 14 & 12.72 & $<0.001$ \\
\hline Cerebellum & $\mathrm{R}$ & 34 & -78 & -34 & 10.80 & $<0.001$ \\
\hline Rolandic operculum & $\mathrm{R}$ & 48 & -22 & 18 & 10.12 & $<0.001$ \\
\hline Angular gyrus & L & -48 & -64 & 26 & 10.08 & $<0.001$ \\
\hline poral gyrus & L & -58 & -8 & -6 & 9.69 & $<0.001$ \\
\hline Fusiform gyrus & $\mathrm{L}$ & -32 & -40 & -12 & 9.60 & $<0.001$ \\
\hline Angular gyrus & $\mathrm{R}$ & 56 & -66 & 36 & 9.25 & $<0.001$ \\
\hline Fusiform gyrus & $\mathrm{R}$ & 30 & -42 & -10 & 7.83 & $=0.007$ \\
\hline Inferior frontal gyr & R & 52 & 32 & 6 & 7.80 & $=0.007$ \\
\hline Inferior orbita & $\mathrm{R}$ & 38 & 36 & -10 & 7.44 & $=0.015$ \\
\hline Cerebellum & L & -26 & -84 & -32 & 7.13 & $=0.025$ \\
\hline vmPFC & $L / R$ & -6 & 46 & 0 & 8.39 & $<0.001^{*}$ \\
\hline \multirow[t]{2}{*}{ Amygdala } & $\mathrm{L}$ & -26 & -10 & -18 & 5.64 & $=0.001^{*}$ \\
\hline & $\mathrm{R}$ & 24 & -8 & -16 & 4.73 & $=0.003^{*}$ \\
\hline \multicolumn{7}{|l|}{ Eye movements $>$ fixation } \\
\hline Calcarine & $\mathrm{R}$ & 6 & -70 & 8 & 7.37 & $<0.001$ \\
\hline \multirow[t]{2}{*}{ Precentral gyrus (FEFs) } & L & -40 & -10 & 50 & 6.57 & $<0.001$ \\
\hline & $\mathrm{R}$ & 32 & -4 & 52 & 8.48 & $=0.002$ \\
\hline \multirow[t]{2}{*}{ Posterior parietal cortex } & R & 28 & -52 & 50 & 5.81 & $=0.001$ \\
\hline & L & -26 & -52 & 54 & 5.77 & $=0.001$ \\
\hline Middle cingulate cortex & L & -12 & -20 & 40 & 5.22 & $=0.018$ \\
\hline \multicolumn{7}{|l|}{ Eye movements $<$ fixation } \\
\hline \multirow[t]{2}{*}{ Amygdala } & L & -24 & -8 & -14 & 3.17 & $=0.035^{*}$ \\
\hline & $\mathrm{R}$ & 28 & -8 & -16 & 3.13 & $=0.08^{*}$ \\
\hline \multirow[t]{2}{*}{ Inferior occipital gyrus } & $\mathrm{R}$ & 34 & -98 & -8 & 5.38 & $=0.008$ \\
\hline & L & -26 & -98 & -10 & 5.31 & $=0.012$ \\
\hline
\end{tabular}

${ }^{2}$ To reduce the number of peak voxels, only the peak voxels in the predefined ROls are reported.

All coordinates are defined in MNI152 space. All statistics listed are significant at $p<0.05$, whole-brain FWEcorrected unless indicated otherwise.

*Small volume corrected for ROI.

of Imaging Neuroscience). Anonymized data will be made available to others upon formal request.

\section{Results}

\section{Experiment 1}

A working-memory task and goal-directed eye movements suppress amygdala activity

In a block design, participants performed a two-back workingmemory task and goal-directed eye movements while undergoing functional MRI. We found typical activation patterns within the dorsal frontoparietal network (Corbetta and Shulman, 2002; Qin et al., 2009) during the two-back (e.g., the left and right dorsolateral PFC: $p<0.001$ peak-voxel FWE-SVC, and left and right posterior parietal cortex: $p<0.001$ peak-voxel FWE-SVC) and eye-movement blocks (e.g., the left and right FEFs: $p<0.001$ peak-voxel FWE-SVC, and left and right posterior parietal cortex: $p<0.001$ peak-voxel FWE-SVC). Further, and as expected, both the two-back blocks (left: $p=0.001$, right: $p=0.003$; peakvoxel FWE-SVC) and eye-movement blocks (left: $p=0.035$; right: $p=0.08$, peak-voxel FWE-SVC) led to deactivations in the amygdala compared with fixation. The amygdala suppression during the eye-movement blocks was not as strong (i.e., suppression was only significant in the left amygdala); however, a direct comparison revealed no difference in amygdala deactivation be-
Table 2. Peak voxel coordinates and statistics of PPI analyses (with the amygdala as a seed) of the two-back task and eye movements compared to fixation (Experiment 1)

\begin{tabular}{llrrrrl}
\hline Region & Side & $x, \mathrm{~mm}$ & $y, \mathrm{~mm}$ & $z, \mathrm{~mm}$ & Peak & $p$ value \\
\hline Two-back blocks $>$ fixation & & & & & & \\
$\quad$ Superior motor area & $\mathrm{R}$ & 2 & -4 & 60 & 11.10 & $<0.001$ \\
Dorsolateral prefrontal cortex (dIPFC) & $\mathrm{L}$ & -4 & 56 & 36 & 6.84 & $<0.001$ \\
& $\mathrm{R}$ & 62 & 6 & 24 & 6.72 & $<0.001$ \\
Posterior parietal cortex & $\mathrm{L}$ & -32 & -40 & 56 & 8.63 & $<0.001$ \\
& $\mathrm{R}$ & 6 & -36 & 48 & 7.36 & $<0.001$ \\
$\quad \mathrm{LmPFC}$ & $\mathrm{L} / \mathrm{R}$ & -2 & 38 & -6 & 6.12 & $<0.001^{*}$ \\
Eye movements $>$ fixation & & & & & & \\
Middle cingulate cortex & $\mathrm{R}$ & 6 & -38 & 34 & 10.21 & $<0.001$ \\
dIPFC & $\mathrm{L}$ & -22 & 40 & 36 & 6.89 & $<0.001$ \\
& $\mathrm{R}$ & 4 & 66 & 10 & 6.52 & $<0.001$ \\
Posterior parietal cortex & $\mathrm{L}$ & -4 & -62 & 30 & 7.47 & $<0.001$ \\
& $\mathrm{R}$ & 52 & -24 & 14 & 7.24 & $<0.001$ \\
Precentral gyrus (FEFs) & $\mathrm{L}$ & -44 & -18 & 46 & 7.01 & $<0.001$ \\
& $\mathrm{R}$ & 44 & -14 & 56 & 7.04 & $<0.001$ \\
vmPFC & $\mathrm{L} / \mathrm{R}$ & -4 & 42 & -2 & 6.44 & $<0.001^{*}$ \\
\hline
\end{tabular}

All coordinates are defined in MNI152 space. All statistics listed are significant at $p<0.05$, whole-brain FWEcorrected unless indicated otherwise. To reduce the number of peak voxels, only the peak voxels in the predefined ROls are reported.

*Small volume corrected for ROI.

tween the two-back and eye-movement blocks. When using the two-back blocks as a functional localizer for the amygdala, the suppression was significant as well (left: $p=0.015$; right: $p=$ 0.044, peak-voxel FWE-SVC), indicating the suppression is in a similar location for both tasks. Among other regions, deactivation was also found in the ventromedial PFC ( $p<0.001$, FWESVC) in the two-back blocks. For all whole-brain activation and deactivation results see Fig. $1 B$ and Table 1 . See Fig. $1 D$ for an illustration of the location of the suppression in the amygdala.

Finally, we conducted a PPI analysis and found enhanced coupling between the amygdala and the dorsal frontoparietal network during both the two-back (e.g., the left and right dorsolateral PFC: $p<0.001$ peak-voxel FWE-SVC) and eye-movement blocks (e.g., the left and right dorsolateral PFC: $p<0.001$ peak-voxel FWE-SVC, and left and right FEFs: $p<0.001$ peak-voxel FWE-SVC). We also found enhanced coupling between the amygdala and ventromedial PFC, during both the two-back ( $p<0.001$ peak-voxel FWE-SVC) and eye-movement blocks ( $p=0.001$ peak-voxel FWE-SVC). For all connectivity results see Fig. $1 C$ and Table 2.

In conclusion, goal-directed eye movements, similar to a working-memory task (Qin et al., 2009), suppress amygdala activity and induce enhanced coupling between the amygdala and regions involved in cognitive regulation of emotion (Ochsner and Gross, 2005).

\section{Experiment 2}

Goal-directed eye movements suppress amygdala activity

First, we investigated amygdala activity in response to the goaldirected eye movements during extinction learning. We analyzed the data in native space to make sure that the effects in the amygdala are not due to signal blurring from the hippocampus into the amygdala (Fig. 3). Replicating Experiment 1, goaldirected eye movements increased FEF activity $\left(F_{(1,23)}=13.11\right.$, $\left.p=0.001, \eta_{p}^{2}=0.36\right)$ compared with fixation. Amygdala activity was decreased $\left(F_{(1,23)}=4.576, p=0.04, \eta_{p}^{2}=0.17\right)$ compared with fixation and there was no interaction with CS (CS+, CS-; $\left.F_{(1,23)}=1.296, p=0.27, \eta_{p}^{2}=0.05\right)$. Thus, in two independent studies we found that goal-directed eye movements suppress amygdala activity (Fig. 3). 
A

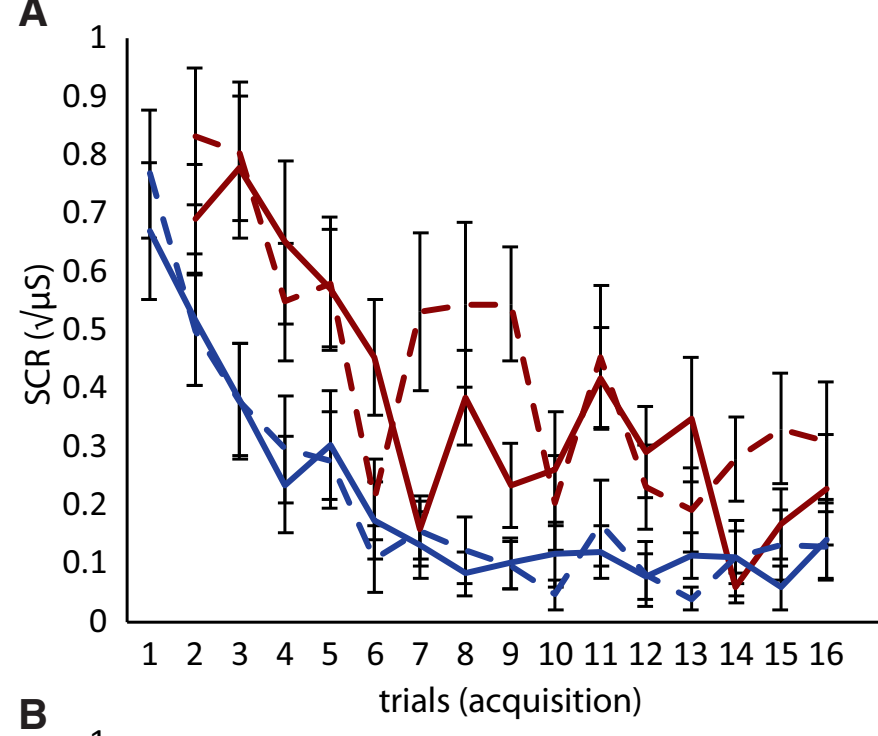

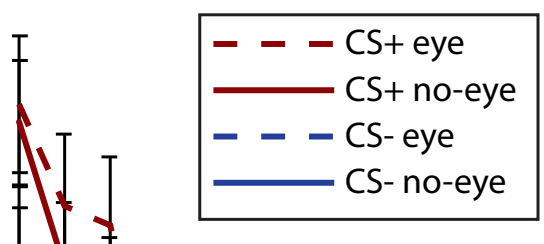

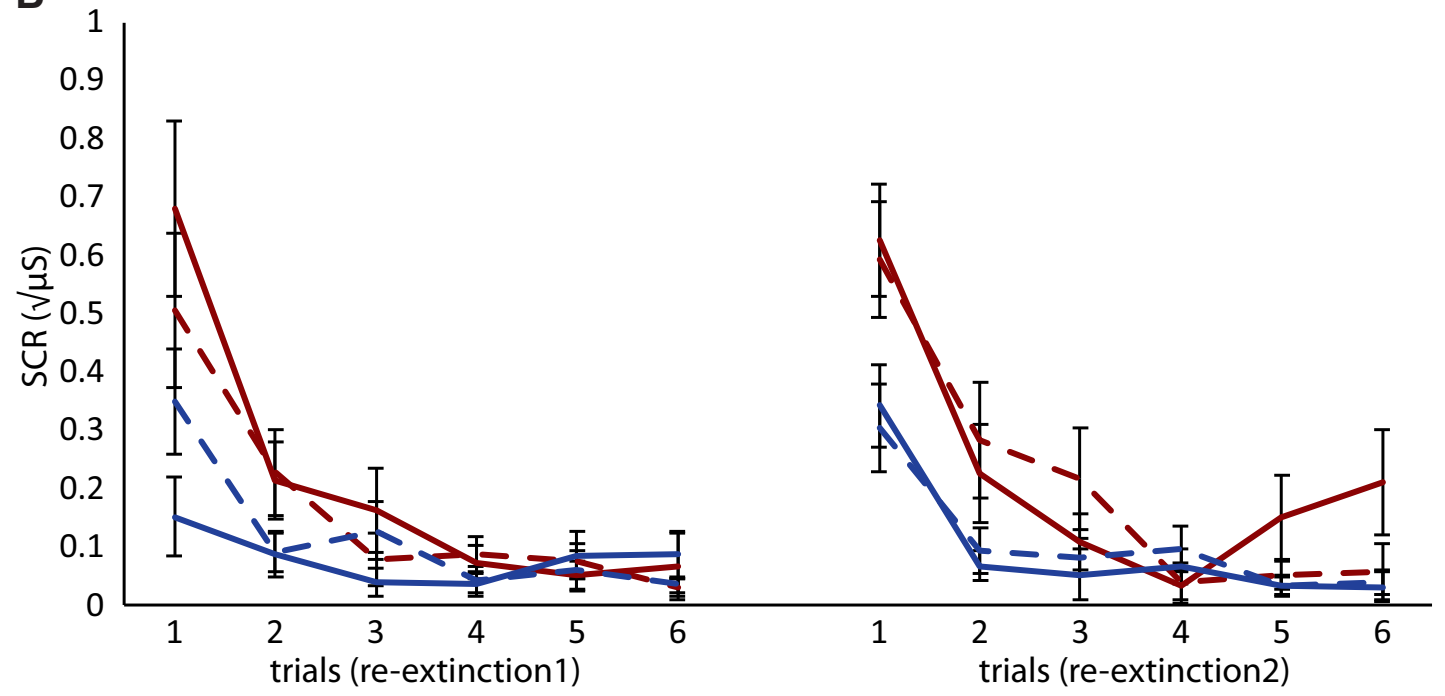

Figure 4. The time course of the SCR measured during $(\boldsymbol{A})$ acquisition and extinction $(\boldsymbol{B})$ re-extinction1, and re-extinction2. Error bars represent \pm SEM. Eye, Eye movements; No-eye, no-eye movements.

Skin conductance responses during fear acquisition and extinction SCR measures during acquisition (Fig. $4 A$ and Fig. $5 A$ ) revealed a robust differential conditioning effect (CS + vs CS - ) across all trials $\left(F_{(1,22)}=18.54, p=2.86 \mathrm{E}-4, \eta_{p}^{2}=0.46\right)$ and there was no interaction with later extinction manipulation (eye, no-eye; $\left.F_{(1,22)}=1.945, p=0.18, \eta_{p}^{2}=0.08\right)$. During early extinction, there was a differential conditioning effect $\left(F_{(1,23)}=49.77, p=\right.$ $\left.3.46 \mathrm{E}-7, \eta_{p}^{2}=0.68\right)$ which became nonsignificant during late extinction $\left(F_{(1,23)}=0.896, p=0.35, \eta_{p}^{2}=0.04\right.$; Fig. $4 B$ and Fig. $5 B)$. There was full extinction on the last trial $\left(F_{(1,23)}=0.260, p=\right.$ $\left.0.61, \eta_{p}^{2}=0.01\right)$ and no interaction with extinction manipulation (eye, no-eye; $F_{(1,23)}=0.991, p=0.33, \eta_{p}^{2}=0.04$ ). Thus, SCR measures revealed there was successful acquisition and extinction, which did not differ significantly between the eye movement and no-eye movement manipulation.

Eye movements during extinction block spontaneous recovery of fear the following day

Crucially, and as predicted, a repeated-measures ANOVA across all re-extinction 1 trials on Day 3 revealed an interaction between extinction manipulation (eye, no-eye) and time (first vs second half of re-extinction $\left.1 ; F_{(1,22)}=6.723, p=0.02, \eta_{p}^{2}=0.23\right)$. Follow-up tests on the spontaneous recovery index, indicated by a differential responding from the last trial of extinction to the first trial of reextinction1 (Schiller et al., 2010), revealed that spontaneous recovery differed between extinction manipulations $\left(F_{(1,22)}=\right.$ $\left.5.976, p=0.02, \eta_{p}^{2}=0.21\right)$. As expected, there was spontaneous recovery for extinction without $\left(t_{(22)}=3.60, p=0.002\right)$, but not with $\left(t_{(22)}=0.694, p=0.50\right.$; Fig. $\left.5 C\right)$ eye movements.

To make sure that this difference in spontaneous recovery was not driven by responses to the CS - rather than by responses to the CS+, we additionally compared responses to the first CSand CS+ during re-extinction 1 . Responses to both CS+ $\left(F_{(1,22)}=4.305, p=0.0499, \eta_{p}^{2}=0.16\right)$ and CS $-\left(F_{(1,22)}=6.705\right.$, $\left.p=0.02, \eta_{p}^{2}=0.23\right)$ differed between eye-movement conditions, showing that the reduction in spontaneous recovery was not driven solely by responses to the CS- .

In sum, eye movements during extinction learning indeed blocked spontaneous recovery.

Eye movement-induced amygdala suppression during extinction predicts a reduction in fear recovery after reinstatement

Analyses on the reinstatement recovery index, indicated by a differential responding from the last trial of re-extinction 1 to the 


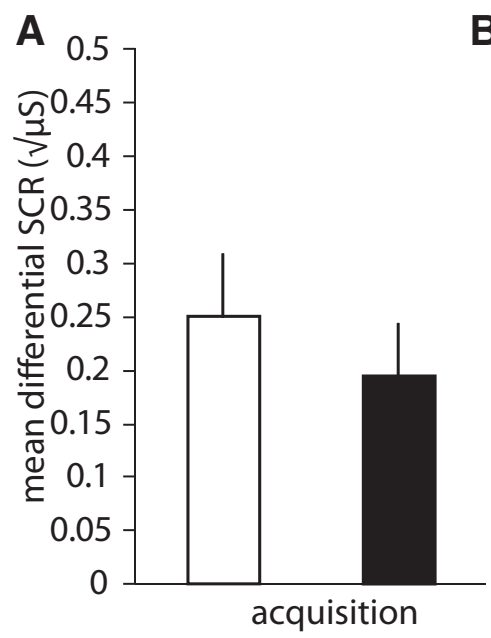

C

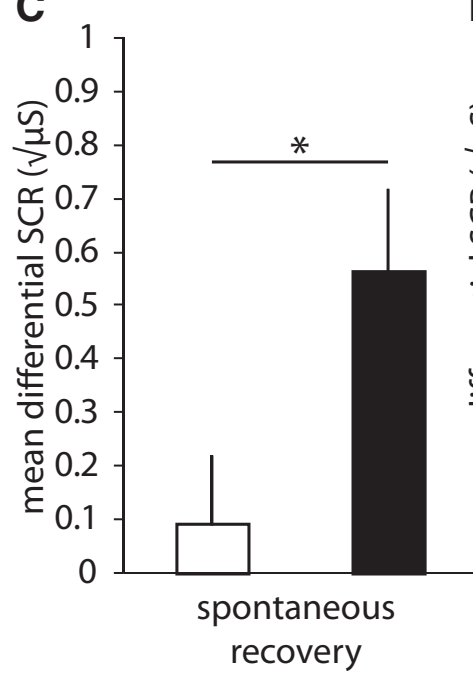

B

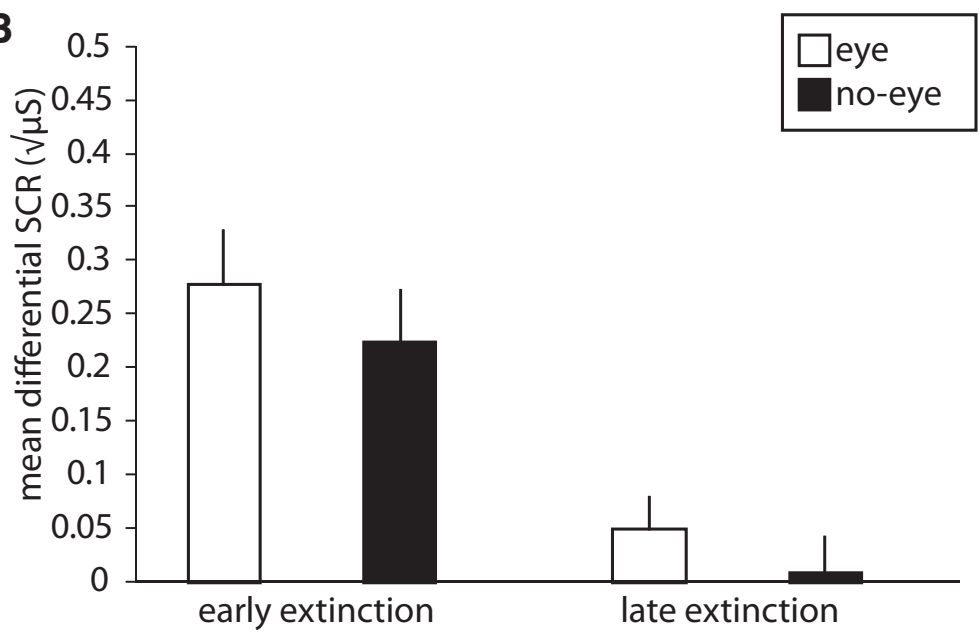

E

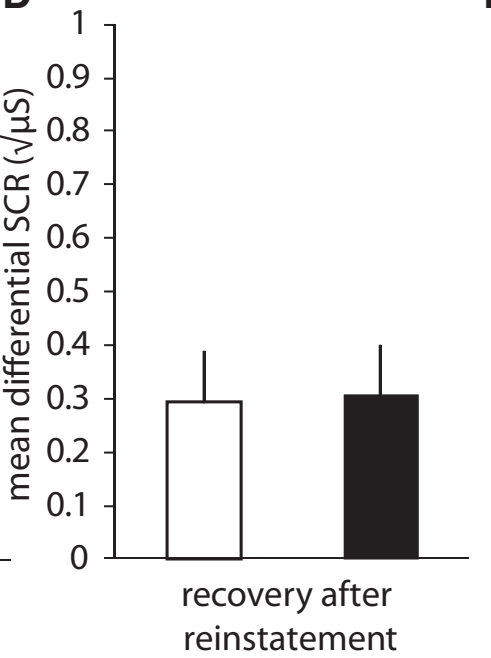

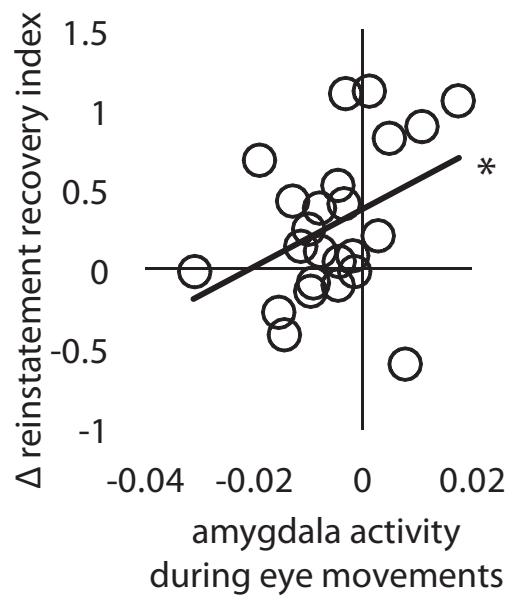

Figure 5. Differential SCRs measured during $(\boldsymbol{A})$ acquisition and $(\boldsymbol{B})$ early and late extinction. $\boldsymbol{C}$, Differential spontaneous recovery index (first trial of re-extinction 1 minus last trial of extinction) and $(\boldsymbol{D})$ differential reinstatement recovery index (first trial re-extinction2 minus last trial re-extinction1). $\boldsymbol{E}$, Correlation between amygdala deactivation during eye-movement blocks on Day 2 and differential reinstatement recovery index for extinction learning with eye movements. Error bars represent $\pm S E M .{ }^{*} p<0.05$. Eye, Eye movements; No-eye, no-eye movements.

first trial of re-extinction2 (Schiller et al., 2010), showed that differential responses returned on average $\left(F_{(1,22)}=23.486, p=\right.$ $\left.7.65 \mathrm{E}-5, \eta_{p}^{2}=0.52\right)$, and that there was no interaction with extinction manipulation $\left(F_{(1,22)}=0.005, p=0.94, \eta_{p}^{2}<0.001\right)$. Notably, including strength of amygdala deactivation as a covariate revealed an interaction between this deactivation and extinction manipulation $\left(F_{(1,21)}=7.252, p=0.01, \eta_{p}^{2}=0.26\right)$. Follow-up tests showed a positive correlation between amygdala deactivation and recovery following reinstatement for the eyemovement manipulation $\left(r_{(21)}=0.39 p=0.028\right.$, one-tailed; Fig. $5 E)$. Amygdala responses during the no-eye movement blocks did not predict recovery following reinstatement $\left(F_{(1,21)}=1.392\right.$, $p=0.25, \eta_{p}^{2}=0.06$ ). Additionally, a Steiger $z$ test (Steiger, 1980) comparing the correlation coefficients in both manipulation types revealed the positive correlation was stronger for the eyemovement manipulation compared with the no-eye movement manipulation $\left(z_{(22)}=2.598, p=0.024\right)$. We furthermore did not find an interaction between extinction manipulation and amygdala deactivation for the spontaneous recovery index $\left(F_{(1,21)}=1.592, p=0.22, \eta_{p}^{2}=0.07\right)$. Amygdala deactivation did, however, predict the difference between the spontaneous recovery index and reinstatement recovery index $\left(r_{(20)}=0.62 p=\right.$ $0.002)$. Responses in the FEFs were not associated with recovery following reinstatement $\left(F_{(1,21)}=0.44, p=0.51, \eta_{p}^{2}=0.02\right)$. To further make sure this effect is specific for the amygdala, we added the reinstatement recovery index as a covariate to a conventional group analysis in standard stereotactic (MNI152) space. With this analysis, we did not find any other region (including the use of SVC for the vmPFC, FEF, and dACC) to be correlated with the reinstatement recovery index other than the right amygdala ( $p=0.024$, peak-voxel FWE-SVC).

In conclusion, differential fear responses on average recovered after reinstatement, however, recovery for the eyemovement condition was attenuated when participants had stronger amygdala deactivations during eye movements.

Whole-brain group analysis in standard stereotactic space We first verified whether the acquisition phase exhibited the expected task-related activation and deactivation during CS presentation using conventional group analyses in standard stereotactic (MNI152) space. We observed robust differential BOLD responses in the anterior insula (left: $p<0.001$, right: $p<0.001$, peak-voxel FWE-corrected) and dACC $(p<0.001$, peak-voxel FWE-corrected) among others. Additionally, we observed robust deactivations in the vmPFC $(p=0.007$, peak-voxel FWEcorrected) among others. See Table 3. 
Table 3. Peak voxel coordinates and statistics during acquisition (Experiment 2)

\begin{tabular}{|c|c|c|c|c|c|c|}
\hline Region & Side & $x, \mathrm{~mm}$ & $y, \mathrm{~mm}$ & $z, \mathrm{~mm}$ & Peak T & $p$ value \\
\hline \multicolumn{7}{|l|}{$\mathrm{CS}+>\mathrm{CS}-$} \\
\hline \multirow[t]{2}{*}{ Inferior frontal gyrus/anterior insula } & $\mathrm{R}$ & 50 & 24 & 4 & 9.6797 & $<0.001$ \\
\hline & L & -36 & 24 & 4 & 8.90 & $<0.001$ \\
\hline Supramarginal gyrus & $\mathrm{R}$ & 54 & -40 & 28 & 8.6493 & $<0.001$ \\
\hline dACC & $\mathrm{R}$ & 8 & 26 & 28 & 7.8007 & $<0.001$ \\
\hline Supramarginal gyrus & L & -54 & -40 & 32 & 6.1253 & $=0.002$ \\
\hline \multirow[t]{2}{*}{ Cerrebellum } & $\mathrm{R}$ & 2 & -54 & -36 & 5.9356 & $=0.004$ \\
\hline & $\mathrm{L}$ & -34 & -54 & -32 & 5.9167 & $=0.004$ \\
\hline \multicolumn{7}{|l|}{$\mathrm{CS}->\mathrm{CS}+$} \\
\hline Middle occipital gyrus & $\mathrm{L}$ & -44 & -74 & 30 & 5.8497 & $=0.006$ \\
\hline Hippocampus & L & -24 & -18 & -18 & 5.8302 & $=0.006$ \\
\hline vmPFC & L & -10 & 52 & -6 & 5.7878 & $=0.007$ \\
\hline Precuneus & R & 10 & -54 & 14 & 5.7507 & $=0.008$ \\
\hline Paracentral lobule & $\mathrm{R}$ & 8 & -26 & 70 & 5.6498 & $=0.012$ \\
\hline Precuneus & $\mathrm{L}$ & -8 & -60 & 16 & 5.6123 & $=0.014$ \\
\hline Fusiform gyrus/para-hippocampal gyrus & $\mathrm{R}$ & 32 & -44 & -4 & 5.3385 & $=0.038$ \\
\hline
\end{tabular}

All coordinates are defined in MNI152 space. All statistics listed are significant at $p<0.05$, whole-brain FWEcorrected unless indicated otherwise.

Next, we investigated response patterns to the CS during extinction learning. First, we found activation patterns in the anterior insula (left: $p=0.016$, right: $p=0.043$, peak-voxel FWEcorrected $)$ and dACC $(p=0.02$, peak-voxel FWE-SCV) as a main effect of CS (CS+ vs CS-). We did not observe any deactivations. Interestingly, similar to what our native space analysis of the FEFs activation already showed (Fig. 3B), we found activation in the FEF in response to the CS that was coupled to the eye movements (left: $p=0.034$, peak-voxel FWE-corrected; right: $p=0.001$, peak-voxel FWE-SVC) as a main effect of eye movements. This was before the execution of the eye movements and thus indicates an anticipation response. There was no CS (CS+, CS-) by extinction manipulation (eye, no-eye) interaction.

Critically, in response to the eye movement blocks (which followed the CS presentation after a brief delay) we found deactivation in the vmPFC ( $p=0.025$, peak-voxel FWE-corrected). See Table 4 for the full whole-brain results. Additional analysis on the vmPFC using the native-space data confirmed vmPFC was deactivated compared with fixation $\left(F_{(1,23)}=7.265, p=0.013\right.$, $\left.\eta_{p}^{2}=0.24\right)$. This deactivation did not predict recovery following reinstatement $\left(F_{(1,23)}=0.065, p=0.801, \eta_{p}^{2}=0.003\right)$. Thus, similar to amygdala responses, $\mathrm{vmPFC}$ responses are suppressed during the eye-movement blocks (Fig. 3).

Finally, during re-extinction1, we found differential BOLD responses $(\mathrm{CS}+\mathrm{vs} \mathrm{CS}-)$ in the anterior insula $(p<0.001$, peakvoxel FWE-corrected). During re-extinction2, we found differential BOLD responses in the dACC $(p<0.001$, peak-voxel FWE-corrected) and there was an interaction with extinction manipulation (eye, no-eye; $p<0.003$, peak-voxel FWE-SVC). We found dACC responses for the no-eye movement manipulation ( $p<0.007$, peak-voxel FWE-corrected), but no differential responses for the eye-movement manipulation was present. This is in line with previous findings (Schiller et al., 2013) and could be because this analysis reflects both the process of recovery as well as the process of re-extinction. See Table 5.

\section{Discussion}

This study aimed to test the hypotheses that goal-directed eye movements, as used in EMDR therapy, can enhance extinction through amygdala suppression. First, we found that goaldirected eye movements (Experiments 1 and 2) as well as a working-memory task (Experiment 1) deactivated the amygdala. Second, we found that both tasks (Experiment 1) altered connec-
Table 4. Peak voxel coordinates and statistics during extinction learning (Experiment 2)

\begin{tabular}{|c|c|c|c|c|c|c|}
\hline Region & Side & $x, \mathrm{~mm}$ & $y, \mathrm{~mm}$ & $z, \mathrm{~mm}$ & Peak T & $p$ value \\
\hline \multicolumn{7}{|l|}{ CS presentation } \\
\hline \multicolumn{7}{|l|}{$\mathrm{CS}+>\mathrm{CS}-[$ main effect $\mathrm{CS}]$} \\
\hline \multirow[t]{2}{*}{ Anterior insula } & $\mathrm{R}$ & 42 & 18 & -6 & 6.36 & $=0.001$ \\
\hline & $\mathrm{L}$ & -32 & 22 & -4 & 5.75 & $=0.009$ \\
\hline \multirow{2}{*}{$\begin{array}{l}\text { Frontal middle orbital cortex } \\
\text { dACC }\end{array}$} & $\mathrm{R}$ & 20 & 60 & -12 & 5.61 & $=0.02$ \\
\hline & $\mathrm{R}$ & 4 & 28 & 30 & 5.31 & $=0.04$ \\
\hline \multicolumn{7}{|c|}{ Eye movements $>$ no-eye movements [main effect eye movements] } \\
\hline Calcrine & $\mathrm{L}$ & 10 & -68 & 18 & 10.82 & $<0.001$ \\
\hline Supplemental motor area & $\mathrm{L}$ & -4 & -6 & 62 & 7.94 & $<0.001$ \\
\hline Posterior parietal cortex & $\mathrm{L}$ & -26 & -52 & 52 & 7.60 & $<0.001$ \\
\hline \multirow{2}{*}{ Precentral gyrus (FEFs) } & $\mathrm{L}$ & -44 & -8 & 52 & 7.58 & $<001$ \\
\hline & $\mathrm{R}$ & 44 & -8 & 50 & 7.94 & $<0.001$ \\
\hline Posterior parietal cortex & $\mathrm{R}$ & 26 & -52 & 48 & 7.53 & $<0.001$ \\
\hline Middle temporal gyrus & $\mathrm{R}$ & 44 & -64 & 10 & 6.26 & $=0.001$ \\
\hline Middle cingulate cortex & $\mathrm{L}$ & -14 & -20 & 38 & 5.98 & $=0.044$ \\
\hline \multicolumn{7}{|l|}{ Eye movement blocks } \\
\hline \multicolumn{7}{|l|}{ Eye movements $>$ fixation } \\
\hline Lingual gyrus & $\mathrm{L}$ & -10 & -88 & -2 & 15.13 & $<0.001$ \\
\hline Precentral gyrus (FEFs) & $\mathrm{R}$ & 48 & -4 & 42 & 10.26 & $<0.001$ \\
\hline Putamen & $\mathrm{L}$ & -22 & -2 & 12 & 9.80 & $<0.001$ \\
\hline Supplemental motor area & $\mathrm{L}$ & -4 & -4 & 62 & 8.21 & $=0.003$ \\
\hline Precentral gyrus (FEFs) & $\mathrm{L}$ & -52 & -4 & 38 & 8.02 & $=0.005$ \\
\hline Putamen & $\mathrm{R}$ & 22 & 8 & 10 & 7.46 & $=0.016$ \\
\hline \multicolumn{7}{|l|}{ Eye movements < fixation } \\
\hline Posterior insula & $\mathrm{R}$ & 38 & -18 & 12 & 11.22 & $<0.001$ \\
\hline Parahippocampal gyrus & $\mathrm{R}$ & 18 & -14 & -24 & 9.16 & $<0.001$ \\
\hline Posterior insula & $\mathrm{L}$ & -36 & -20 & 8 & 8.99 & $=0.001$ \\
\hline Inferior occipital gyrus & $\mathrm{R}$ & 32 & -96 & -4 & 7.80 & $=0.008$ \\
\hline Superior parietal gyrus & $\mathrm{R}$ & 18 & -44 & 68 & 7.44 & $=0.017$ \\
\hline Inferior occipital gyrus & $\mathrm{L}$ & -28 & -94 & -6 & 7.34 & $=0.020$ \\
\hline vmPFC & $\mathrm{L}$ & -8 & 24 & -12 & 7.22 & $=0.025$ \\
\hline Post-central gyrus & $\mathrm{R}$ & 44 & -26 & 54 & 7.01 & $=0.036$ \\
\hline Amygdala & $\mathrm{R}$ & 32 & 4 & -20 & 4.43 & $=0.008^{*}$ \\
\hline
\end{tabular}

All coordinates are defined in MNI152 space. All statistics listed are significant at $p<0.05$, whole-brain FWEcorrected unless indicated otherwise.

*Small volume corrected for ROl.

Table 5. Peak voxel coordinates and statistics during re-extinction 1 and re-extinction2 (Experiment 2)

\begin{tabular}{|c|c|c|c|c|c|c|}
\hline Region & Side & $x, \mathrm{~mm}$ & $y, \mathrm{~mm}$ & $z, \mathrm{~mm}$ & Peak T & $p$ value \\
\hline \multicolumn{7}{|l|}{ Re-extinction1 } \\
\hline \multicolumn{7}{|l|}{$\mathrm{CS}+>\mathrm{CS}-$} \\
\hline Anterior insula & $\mathrm{R}$ & 50 & 20 & -2 & 6.3 & $<0.001$ \\
\hline \multicolumn{7}{|l|}{ Re-extinction2 } \\
\hline \multicolumn{7}{|l|}{$\mathrm{CS}+>\mathrm{CS}-$} \\
\hline Dorsal anterior cingulate cortex & $\mathrm{R}$ & 8 & 26 & 50 & 5.52 & $=0.024$ \\
\hline Thalamus & $\mathrm{R}$ & 6 & -6 & 2 & 5.52 & $=0.024$ \\
\hline \multicolumn{7}{|c|}{ CS by extinction manipulation interaction } \\
\hline Dorsal anterior cingulate cortex & $\mathrm{L}$ & -8 & 28 & 38 & 4.89 & $=0.003^{*}$ \\
\hline \multicolumn{7}{|l|}{$\mathrm{CS}+>\mathrm{CS}-[$ no-eye movements $]$} \\
\hline Dorsal anterior cingulate cortex & $\mathrm{R}$ & 8 & 36 & 40 & 6.24 & $=0.007$ \\
\hline
\end{tabular}

All coordinates are defined in MNI152 space. All statistics listed are significant at $p<0.05$, whole-brain FWEcorrected unless indicated otherwise.

*Small volume corrected for ROI.

tivity between the amygdala and the dorsal frontoparietal network as well as connectivity between the amygdala and the ventromedial prefrontal cortex. Third, a precisely timed application of the eye movements during extinction learning blocked spontaneous recovery $24 \mathrm{~h}$ later (Experiment 2). Fourth, although fear responses on average recovered after reinstatement, recovery was attenuated when participants had stronger amygdala deactivations during eye movements (Experiment 2). Given that 
we found similar amygdala suppression in another task taxing working memory (Experiment 1), the reported effects on fear recovery are likely not specific to eye movements.

A potential explanation for why amygdala deactivation occurs, is that large-scale brain networks act reciprocally (Fox et al., 2005) and compete for resources (Hermans et al., 2014). Acute stress engages the amygdala but impairs dorsal frontoparietal network functioning (Hermans et al., 2014). Our data confirm that engaging the dorsal frontoparietal network has the opposite effect of deactivating the amygdala. We furthermore found coupling between the amygdala and dorsolateral as well as ventromedial prefrontal pathways. The vmPFC plays a crucial role in extinction learning and is thought to mediate dorsolateral PFCamygdala interactions (Delgado et al., 2008). Our finding aligns closely with the literature on cognitive regulation of emotion (Ochsner and Gross, 2005), while revealing that mere eye movements are sufficient to engage these pathways.

A consequence of this resource competition might be that fear expression is attenuated. Startle responses, for instance, are reduced when performing a working-memory task (Vytal et al., 2012) and patients with amygdala lesions show enhanced working memory performance (Morgan et al., 2012). If this mechanism underlies the role of eye movements in reducing traumatic symptoms, then any task taxing working memory should have similar effects. Indeed, emotionality and vividness of autobiographical memories as well as intrusive memories are reduced when memory reactivation is paired with working-memory tasks (Holmes et al., 2009; Engelhard et al., 2010; James et al., 2015). Last, other types of cognitive control, such as emotion regulation, suppress amygdala activity and alter emotionality during autobiographical memory recollection (Denkova et al., 2015). Our data therefore provide an explanation for how both eye movements and tasks involving cognitive control could affect the emotionality of memories.

Spontaneous recovery was diminished after extinction with eye movements. The dominant view on post-extinction recovery (Maren, 2011; Dunsmoor et al., 2015b) holds that this can be due to updating the original CS-US association or to the formation of a stronger new extinction memory. In line with the latter account, differential fear responses recovered after reinstatement, indicating the CS-US association was not fully eliminated. A similar reduction in spontaneous recovery was observed in a study in which the US was replaced by a nonaversive tone during extinction (Dunsmoor et al., 2015a). One possibility, therefore, is that eye movements following the CS presentation, similar to a tone, strengthen extinction by reducing the ambiguity of the CS either predicting the US or not predicting anything. Unlike a tone, however, eye movements suppress amygdala activity and possibly attenuate fear responses (Vytal et al., 2012). This may allow for additional learned controllability over conditioned responses via subsequent suppression. This interpretation aligns with findings of reduced spontaneous recovery in rats when trained to actively avoid the US during extinction learning (Moscarello and LeDoux, 2013).

The amygdala is, additionally, crucially involved in encoding the CS-US association (Maren, 2011). Amygdala suppression following reactivation could therefore also have led to updating of the CS-US association (e.g., as less aversive) rather than only facilitating new learning. Although the finding that fear recovered following reinstatement would speak against this explanation, this finding is not conclusive on whether the eye movements in EMDR therapy induce unlearning or new learning. Disentangling unlearning from new learning in a laboratory experiment relying on behavioral observations in humans is problematic, since any behavioral outcome is consistent with multiple explanations. Moreover, recent views on safety learning challenge a strict dichotomy between unlearning and new learning (Clem and Schiller, 2016). Future studies using an animal model of EMDR, in combination with techniques with which a memory trace modification can be measured, could shed more light on this matter. For example, using engram-based tagging techniques, a recent study showed how specific neurons are activated during learning and recall of fear memories, and how these are related to fear attenuation (Khalaf et al., 2018). Together, we propose that eye movements during extinction learning may affect fear recovery by enhancing extinction via newly learned instrumental control over CS-evoked fear responses following memory reactivation (Moscarello and LeDoux, 2013), possibly through pathways engaged during cognitive regulation of emotion (Ochsner and Gross, 2005).

The observed amygdala suppression was located toward the dorsal rather than ventral part. However, we are hesitant in assigning this deactivation to a specific subregion. A comparison between dorsal and ventral is difficult due to inherent problems of gradient EPI sequences, such as signal loss or distortions, which are increased toward the ventral part of the brain (Merboldt et al., 2001; Sladky et al., 2013). These inherent problems (i.e., distance between a brain area and the head coil or cavities) cannot be fully resolved (Merboldt et al., 2001; Sladky et al., 2013). Whether the effect we observed can be attributed to a specific subregion of the amygdala therefore remains an open question.

We found anticipatory FEF activation in response to the CS coupled with eye movements before eye movements took place. This is in line with anticipatory responses observed using electrophysiological recordings in monkeys (Zhou and Thompson, 2009). In our study, the CS $+_{\text {eye }}$ and CS $-{ }_{\text {eye }}$ always predicted an eye-movement block, therefore anticipatory responses could be expected. Only five of 24 participants reported the association between the CS and the eye-movement blocks. Excluding these participants did not affect the results. The FEF activation, moreover, did not predict the reduction in spontaneous recovery, suggesting the anticipatory responses in the FEF did not affect fear recovery.

Despite EMDR being an evidence-based therapy (Bisson et al., 2013; Lee and Cuijpers, 2013), it has received substantial criticism (Devilly, 2002; Rogers and Silver, 2002). Our results shed new light on the working mechanisms of this treatment. One account of EMDR holds that, unlike exposure therapy (Maren, 2011; Bisson et al., 2013), EMDR induces unlearning (Shapiro, 1989; Devilly, 2002; van den Hout and Engelhard, 2012). We found evidence speaking against this claim, since fear recovered following reinstatement. However, as explained above, it is possible that our design did not capture all processes that occur during EMDR treatment, therefore, further research is necessary to investigate whether EMDR may involve unlearning. Future studies could focus on incorporating eye movements in paradigms that more likely capture reconsolidation (Schiller et al., 2013; James et al., 2015).

Another controversy regarding EMDR concerns the role of eye movements, which some regard as crucial (Shapiro, 1989), whereas others argue they have no added value (Rogers and Silver, 2002) or merely serve as a distractor (Devilly, 2002). Our data demonstrate that eye movements have added value above standard extinction learning. However, the data from Experiment 1 suggest that any task taxing working memory would suppress 
amygdala activity and have similar effects. Indeed, there is a large body of research indicating that working-memory tasks reduce the emotionality of memories (Engelhard et al., 2011) as well as memory intrusions (Holmes et al., 2009; James et al., 2015; Iyadurai et al., 2018). These manipulations have also been shown to be effective in a clinical setting (Iyadurai et al., 2018). Only tasks with a working-memory load appear to have such effects, whereas visual distraction by itself does not (Onderdonk and van den Hout, 2016). Our data are also in line with studies using other types of focused attention, such as emotion regulation strategies (Denkova et al., 2015), which are accompanied by amygdala suppression as well. In sum, although other manipulations may have a similar effect, our data support the view that eye movements have a functional role in EMDR.

Several limitations regarding our study need to be mentioned. First, some of our findings are only just statistically significant, and were obtained in a limited sample $(n=24$ in each experiment). Although amygdala suppression due to eye movements was replicated across experiments, the effect on extinction learning was only tested in Experiment 2 and therefore awaits independent replication. Second, the experimental model of EMDR we developed in this study has inherent limitations because it is impossible to capture every aspect of this therapy (e.g., regarding timing of trauma recall and eye movements, or effects of repeated sessions) in a controlled experiment. Future studies should therefore focus on (1) establishing the reproducibility and generalizability of our findings, (2) investigating the specificity of the observed effects on extinction learning to eye movements, and (3) further illuminating the causal chain from taxing working memory to amygdala suppression and enhanced extinction learning.

In conclusion, our findings show eye movements have added value in safety learning above standard extinction alone. This effect, while likely not specific to eye movements, is associated with amygdala deactivation possibly as a consequence of reciprocally coupled activation of the dorsal frontoparietal network, via ventromedial prefrontal pathways similar to those involved in cognitive regulation of emotion. A key advantage of amygdala deactivation through behavioral manipulations, rather than via pharmacological treatments, is that they are noninvasive, precise in time and duration, and shown to be clinically effective (Bisson et al., 2013). Our findings provide a parsimonious account for how a wide range of behavioral manipulations including working-memory tasks, a game of Tetris, and eye movements can alter retention of emotional memories.

\section{References}

Agren T, Engman J, Frick A, Björkstrand J, Larsson EM, Furmark T, Fredrikson M (2012) Disruption of reconsolidation erases a fear memory trace in the human amygdala. Science 337:1550-1552. CrossRef Medline

Ashburner J (2007) A fast diffeomorphic image registration algorithm. Neuroimage 38:95-113. CrossRef Medline

Ashburner J, Friston KJ (2005) Unified segmentation. Neuroimage 26:839851. CrossRef Medline

Beck A, Steer R, Brown G (1996) Beck depression inventory-II. San Antonio, TX: Pearson.

Birn RM, Diamond JB, Smith MA, Bandettini PA (2006) Separating respiratory-variation-related fluctuations from neuronal-activity-related fluctuations in fMRI. Neuroimage 31:1536-1548. CrossRef Medline

Bisson JI, Roberts NP, Andrew M, Cooper R, Lewis C (2013) Psychological therapies for chronic post-traumatic stress disorder (PTSD) in adults. Cochrane Database Syst Rev 12:CD003388. CrossRef Medline

Bos MG, Beckers T, Kindt M (2012) The effects of noradrenergic blockade on extinction in humans. Biol Psychol 89:598-605. CrossRef Medline

Clem RL, Schiller D (2016) New learning and unlearning: strangers or ac- complices in threat memory attenuation? Trends Neurosci 39:340-351. CrossRef Medline

Corbetta M, Shulman GL (2002) Control of goal-directed and stimulusdriven attention in the brain. Nat Rev Neurosci 3:201-215. CrossRef Medline

Dębiec J, Ledoux JE (2004) Disruption of reconsolidation but not consolidation of auditory fear conditioning by noradrenergic blockade in the amygdala. Neuroscience 129:267-272. CrossRef Medline

Delgado MR, Nearing KI, Ledoux JE, Phelps EA (2008) Neural circuitry underlying the regulation of conditioned fear and its relation to extinction. Neuron 59:829-838. CrossRef Medline

Denkova E, Dolcos S, Dolcos F (2015) Neural correlates of "distracting" from emotion during autobiographical recollection. Soc Cogn Affect Neurosci 10:219-230. CrossRef Medline

Devilly GJ (2002) Eye movement desensitization and reprocessing: a chronology of its development and scientific standing. Sci Rev Ment Heal Practice 1:113-138.

Dunsmoor JE, Campese VD, Ceceli AO, LeDoux JE, Phelps EA (2015a) Novelty-facilitated extinction: providing a novel outcome in place of an expected threat diminishes recovery of defensive responses. Biol Psychiatry 78:203-209. CrossRef Medline

Dunsmoor JE, Niv Y, Daw N, Phelps EA (2015b) Rethinking extinction. Neuron 88:47-63. CrossRef Medline

Edelberg R (1972) Electrodermal recovery rate, goal-orientation, and aversion. Psychophysiology 9:512-520. CrossRef Medline

Engelhard IM, van den Hout MA, Smeets MA (2011) Taxing working memory reduces vividness and emotional intensity of images about the Queen's day tragedy. J Behav Ther Exp Psychiatry 42:32-37. CrossRef Medline

Engelhard IM, van Uijen SL, van den Hout MA (2010) The impact of taxing working memory on negative and positive memories. Eur J Psychotraumatol 1:5623. CrossRef

Fox MD, Snyder AZ, Vincent JL, Corbetta M, Van Essen DC, Raichle ME (2005) The human brain is intrinsically organized into dynamic, anticorrelated functional networks. Proc Natl Acad Sci U S A 102:9673-9678. CrossRef Medline

Friston KJ, Buechel C, Fink GR, Morris J, Rolls E, Dolan RJ (1997) Psychophysiological and modulatory interactions in neuroimaging. Neuroimage 6:218-229. CrossRef Medline

Gitelman DR, Penny WD, Ashburner J, Friston KJ (2003) Modeling regional and psychophysiologic interactions in fMRI: the importance of hemodynamic deconvolution. Neuroimage 19:200-207. CrossRef Medline

Glover GH, Li TQ, Ress D (2000) Image-based method for retrospective correction of physiological motion effects in fMRI: RETROICOR. Magn Reson Med 44:162-167. CrossRef Medline

Green SR, Kragel PA, Fecteau ME, LaBar KS (2014) Development and validation of an unsupervised scoring system (Autonomate) for skin conductance response analysis. Int J Psychophysiol 91:186-193. CrossRef Medline

Griswold MA, Jakob PM, Heidemann RM, Nittka M, Jellus V, Wang J, Kiefer B, Haase A (2002) Generalized autocalibrating partially parallel acquisitions (GRAPPA). Magn Reson Med 47:1202-1210. CrossRef Medline

Haaker J, Golkar A, Hermans D, Lonsdorf TB (2014) A review on human reinstatement studies: an overview and methodological challenges. Learn Mem 21:424-440. CrossRef Medline

Heeger DJ, Ress D (2002) What does fMRI tell us about neuronal activity? Nat Rev Neurosci 3:142-151. CrossRef Medline

Hermans EJ, Henckens MJ, Joëls M, Fernández G (2014) Dynamic adaptation of large-scale brain networks in response to acute stressors. Trends Neurosci 37:304-314. CrossRef Medline

Hermans EJ, Henckens MJ, Roelofs K, Fernández G (2013) Fear bradycardia and activation of the human periaqueductal grey. Neuroimage 66:278287. CrossRef Medline

Holmes EA, James EL, Coode-Bate T, Deeprose C (2009) Can playing the computer game "Tetris" reduce the build-up of flashbacks for trauma? A proposal from cognitive science. PLoS One 4:e4153. CrossRef Medline

Hurlemann R, Walter H, Rehme AK, Kukolja J, Santoro SC, Schmidt C, Schnell K, Musshoff F, Keysers C, Maier W, Kendrick KM, Onur OA (2010) Human amygdala reactivity is diminished by the $\beta$-noradrenergic antagonist propranolol. Psychol Med 40:1839-1848. CrossRef Medline

Iyadurai L, Blackwell SE, Meiser-Stedman R, Watson PC, Bonsall MB, Geddes 
JR, Nobre AC, Holmes EA (2018) Preventing intrusive memories after trauma via a brief intervention involving Tetris computer game play in the emergency department: a proof-of-concept randomized controlled trial. Mol Psychiatry 23:674-682. CrossRef Medline

Jamadar SD, Fielding J, Egan GF (2013) Quantitative meta-analysis of fMRI and PET studies reveals consistent activation in fronto-striatal-parietal regions and cerebellum during antisaccades and prosaccades. Front Psychol 4:749. CrossRef Medline

James EL, Bonsall MB, Hoppitt L, Tunbridge EM, Geddes JR, Milton AL, Holmes EA (2015) Computer game play reduces intrusive memories of experimental trauma via reconsolidation-update mechanisms. Psychol Sci 26:1201-1215. CrossRef Medline

Khalaf O, Resch S, Dixsaut L, Gorden V, Glauser L, Gräff J (2018) Reactivation of recall-induced neurons contributes to remote fear memory attenuation. Science 360:1239-1242. CrossRef Medline

Kindt M, Soeter M (2013) Reconsolidation in a human fear conditioning study: a test of extinction as updating mechanism. Biol Psychol 92:43-50. CrossRef Medline

Kindt M, Soeter M, Vervliet B (2009) Beyond extinction: erasing human fear responses and preventing the return of fear. Nat Neurosci 12:256258. CrossRef Medline

Lee CW, Cuijpers P (2013) A meta-analysis of the contribution of eye movements in processing emotional memories. J Behav Ther Exp Psychiatry 44:231-239. CrossRef Medline

Maren S (2011) Seeking a spotless mind: extinction, deconsolidation, and erasure of fear memory. Neuron 70:830-845. CrossRef Medline

Merboldt KD, Fransson P, Bruhn H, Frahm J (2001) Functional MRI of the human amygdala? Neuroimage 14:253-257. CrossRef Medline

Moore M, Hu Y, Woo S, O'Hearn D, Iordan AD, Dolcos S, Dolcos F (2014) A comprehensive protocol for manual segmentation of the medial temporal lobe structures. J Vis Exp 89:e50991. CrossRef Medline

Morgan B, Terburg D, Thornton HB, Stein DJ, van Honk J (2012) Paradoxical facilitation of working memory after basolateral amygdala damage. PLoS One 7:e38116. CrossRef Medline

Moscarello JM, LeDoux JE (2013) Active avoidance learning requires prefrontal suppression of amygdala-mediated defensive reactions. J Neurosci 33:3815-3823. CrossRef Medline

Nader K, Schafe GE, Le Doux JE (2000) Fear memories require protein synthesis in the amygdala for reconsolidation after retrieval. Nature 406: 722-726. CrossRef Medline

Ochsner KN, Gross JJ (2005) The cognitive control of emotion. Trends Cogn Sci 9:242-249. CrossRef Medline

Onderdonk SW, van den Hout MA (2016) Comparisons of eye movements and matched changing visual input. J Behav Ther Exp Psychiatry 53:3440. CrossRef Medline

O’Reilly JX, Woolrich MW, Behrens TE, Smith SM, Johansen-Berg H (2012) Tools of the trade: psychophysiological interactions and functional connectivity. Soc Cogn Affect Neurosci 7:604-609. CrossRef Medline

Poser BA, Versluis MJ, Hoogduin JM, Norris DG (2006) BOLD contrast sensitivity enhancement and artifact reduction with multiecho EPI: parallel-acquired inhomogeneity-desensitized fMRI. Magn Reson Med 55:1227-1235. CrossRef Medline

Qin S, Hermans EJ, van Marle HJ, Luo J, Fernández G (2009) Acute psychological stress reduces working memory-related activity in the dorsolateral prefrontal cortex. Biol Psychiatry 66:25-32. CrossRef Medline

Rissman J, Gazzaley A, D’Esposito M (2004) Measuring functional connectivity during distinct stages of a cognitive task. Neuroimage 23:752-763. CrossRef Medline

Rogers S, Silver SM (2002) Is EMDR an exposure therapy? A review of trauma protocols. J Clin Psychol 58:43-59. CrossRef Medline

Schiller D, Delgado MR (2010) Overlapping neural systems mediating extinction, reversal and regulation of fear. Trends Cogn Sci 14:268-276. CrossRef Medline

Schiller D, Kanen JW, LeDoux JE, Monfils MH, Phelps EA (2013) Extinction during reconsolidation of threat memory diminishes prefrontal cortex involvement. Proc Natl Acad Sci U S A 110:20040-20045. CrossRef Medline

Schiller D, Monfils MH, Raio CM, Johnson DC, Ledoux JE, Phelps EA (2010) Preventing the return of fear in humans using reconsolidation update mechanisms. Nature 463:49-53. CrossRef Medline

Shapiro F (1989) Eye movement desensitization: a new treatment for posttraumatic stress disorder. J Behav Ther Exp Psychiatry 20:211-217. CrossRef Medline

Shirer WR, Ryali S, Rykhlevskaia E, Menon V, Greicius MD (2012) Decoding subject-driven cognitive states with whole-brain connectivity patterns. Cereb Cortex 22:158-165. CrossRef Medline

Sladky R, Baldinger P, Kranz GS, Tröstl J, Höflich A, Lanzenberger R, Moser E, Windischberger C (2013) High-resolution functional MRI of the human amygdala at 7 T. Eur J Radiol 82:728-733. CrossRef Medline

Steiger JH (1980) Tests for comparing elements of a correlation matrix. Psychol Bull 87:245-251. CrossRef

van Buuren M, Gladwin TE, Zandbelt BB, van den Heuvel M, Ramsey NF, Kahn RS, Vink M (2009) Cardiorespiratory effects on default-mode network activity as measured with fMRI. Hum Brain Mapp 30:30313042. CrossRef Medline

van den Hout MA, Bartelski N, Engelhard IM (2013) On EMDR: eye movements during retrieval reduce subjective vividness and objective memory accessibility during future recall. Cogn Emot 27:177-183. CrossRef Medline

van den Hout MA, Engelhard IM (2012) How does EMDR work? J Exp Psychopathol 3:724-738. CrossRef

Van der Ploeg HM (1980) Validity of the Zelf-Beoordelings-Vragenlijst (a Dutch version of the Spielberger State-Trait Anxiety Inventory). Ned Tijdschr voor Psychol en haar Grensgebieden 35:243-249.

Vytal K, Cornwell B, Arkin N, Grillon C (2012) Describing the interplay between anxiety and cognition: from impaired performance under low cognitive load to reduced anxiety under high load. Psychophysiology 49: 842-852. CrossRef Medline

Zhou HH, Thompson KG (2009) Cognitively directed spatial selection in the frontal eye field in anticipation of visual stimuli to be discriminated. Vision Res 49:1205-1215. CrossRef Medline 